\title{
Investigación arqueológica en un asentamiento rural del Valle de Ayacucho, Perú
}

\section{Archaeological research in a rural settlement in the Ayacucho Valley, Peru}

\author{
Lidio M. Valdez \\ https://orcid.org/0000-0003-1931-2728 \\ University of Calgary, Canadá \\ lidiog@yahoo.es \\ J. Ernesto Valdez \\ https://orcid.org/0000-0002-8629-8279 \\ Universidad de Huamanga, Ayacucho, Perú \\ ernestovaldezcardenas@hotmail.com
}

\section{RESUMEN}

La manera como el centro urbano de Huari del valle de Ayacucho llegó a establecerse es un tema de mucho interés. Sin embargo, el tema sigue siendo poco discutido. Teniendo en consideración información arqueológica recuperada de un asentamiento rural que existió en lo que vino a constituir la periferia de Huari, aquí discutimos el proceso social que parece haberse dado en el valle de Ayacucho entre el final del Periodo Intermedio Temprano e inicios del Horizonte Medio. La evidencia en consideración sugiere el abandono de muchos poblados rurales a finales del Periodo Intermedio Temprano, cuando sus habitantes parecen haber buscado refugio en centros que ofrecieron mayor protección. Todo esto parece haber ocurrido en medio de la violencia que empezó a incrementarse. De este modo, los asentamientos huarpa, viables por generaciones, se vieron obligados a quedar desocupados cuando sus habitantes llegaron a concentrarse en centros específicos como Huari.

Palabras Claves: Huarpa; Huari; Wari; Horizonte Medio; Valle de Ayacucho; Conflicto; Nucleación. 


\title{
ABSTRACT
}

The manner the urban center of Huari of the Peruvian central highlands was established is an important topic. However, the issue remains little discussed. Taking into consideration information gathered from a huarpa settlement that existed in what eventually became the periphery of Huari, we discuss the way Huari achieved a great transformation late during the Early Intermediate Period and early during the Middle Horizon. The evidence suggests that at the end of the Early Intermediate Period a series of huarpa settlements were deserted in what appears to be a very conflictive situation. The former inhabitants of the rural huarpa villages found their way into much larger and better protected settlements. In this manner, a considerable number of huarpa settlements, that were viable for centuries, were deserted as their inhabitants moved specific centers such as Huari.

Key Words: Huarpa; Huari; Wari; Middle Horizon; Ayacucho Valley; Conflict; Nucleation

Recibido: 06/02/2017 - Aceptado: 16/11/2020 - Publicado: 10/05/2021

\section{INTRODUCCIÓN}

\begin{abstract}
"El mayor río de ellos tiene por nombre Vinaque, adonde están unos grandes y muy antiquísimos edificios, que cierto, según están gastados y ruinados, debe de haber pasado por ellos muchas edades. Preguntando a los indios comarcanos quién hizo aquella antigualla, responden otras gentes barbadas y blancas como nosotros, los cuales, muchos tiempos antes que los incas reinasen, dicen que vinieron a estas partes e hicieron allí su morada" (Cieza de León, 1973, p. 207).
\end{abstract}

Entre los años 1548 y 1550, Pedro Cieza de León viajó por el Camino Real Inka de la sierra central del Perú con destino al Cusco, la antigua capital del Tawantinsuyu. Durante su recorrido por la antigua Guamanga (valle de Ayacucho), Cieza de León observó en las inmediaciones de Wiñaq Mayu (Río Pongora) antiguas estructuras que sobresalían por su dimensión y que, de la información proporcionada por los vecinos, habrían sido edificadas mucho tiempo antes de la hegemonía Inka. Al parecer en referencia al río que cruza por sus inmediaciones, el antiguo asentamiento con las estructuras arriba anotadas fue identificado con el mismo nombre, Wiñaq, pero que la misma posteriormente se transformó en Viñaqui y más recientemente en Wari / Huari. De este modo, Huari ${ }^{1}$ está entre los sitios arqueológicos de los Andes Centrales que fue registrado de forma escrita bastante temprano (ver figura 01). Sin embargo, y no obstante su temprano registro, Huari entró al olvido hasta que, finalmente, J. C. Tello en 1931 empezó a prestar atención a su estudio (Lumbreras,

1. Escribimos Huari con $\mathrm{H}$ para referimos al sitio arqueológico, mientras que Wari con W para referirnos al estado Wari. 
1960, p. 131; Isbell \& McEwan, 1991, p. 1; Schreiber, 1992, p. 79). Con la excepción de algunos reportes que salieron en los periódicos de la capital, el defecto de Tello fue no publicar, y ese fue el caso específico de su visita a Huari. Sin embargo, la noticia acerca de Huari captó la atención de otros investigadores, como Alfred Kroeber (1944, p. 99), Gordon Willey (1948, p. 13) y Wendell Bennett y Junius Bird (1949, p. 142-143), quienes no tardaron en sugerir que el centro de dispersión del hasta entonces llamado estilo Tiahuanacoide, tal vez, fue el sitio de Huari de la sierra central del Perú.

En 1946, John H. Rowe, Donald Collier y Gordon Willey hicieron una visita breve a Huari y de inmediato reconocieron su enorme extensión. Las iniciales observaciones hechas por estos investigadores (Rowe, Collier \& Willey, 1950, p. 122), más los siguientes esfuerzos de Bennett (1953), Lumbreras (1960) y Menzel (1964), marcó el punto de inicio de otros estudios (Isbell, 1984, 1988, 1991; Isbell, Brewster-Wray \& Spic-

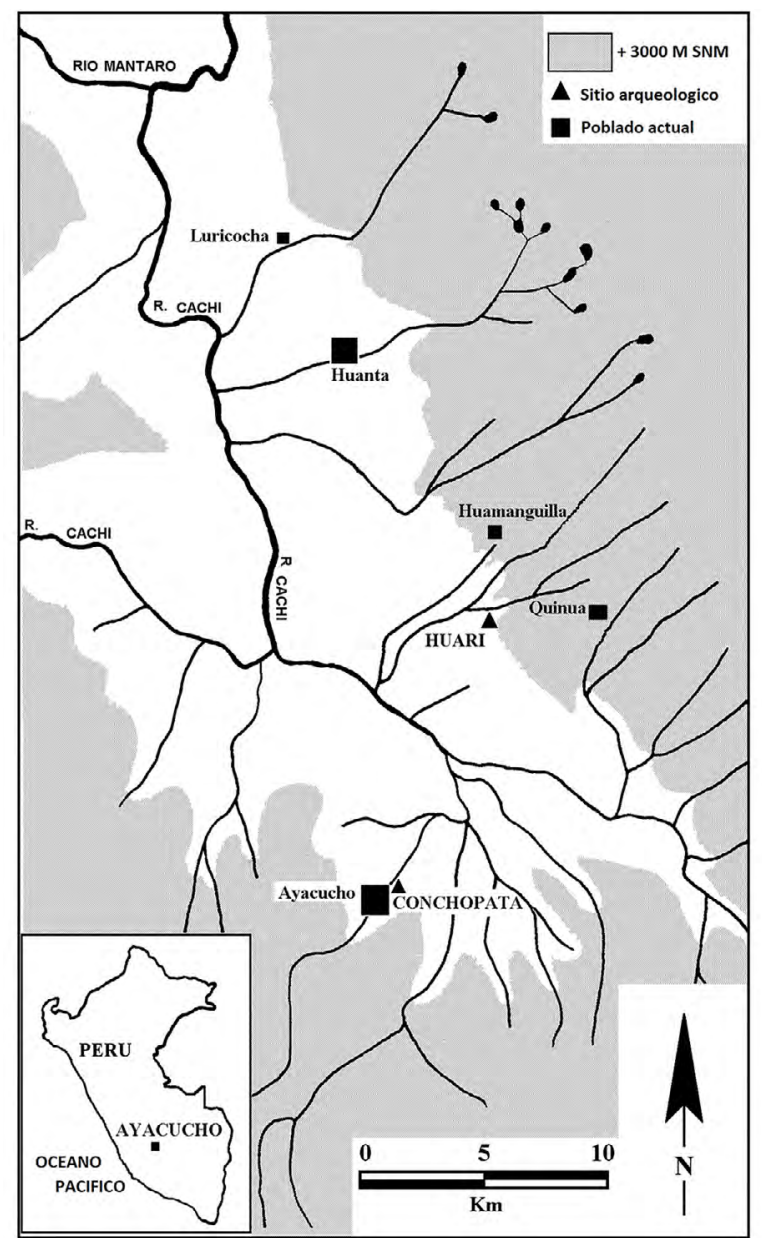

Figura 01. Mapa de ubicación de los sitios los arqueológicos de Huari y Conchopata en el valle de Ayacucho. kard, 1991) efectuados especialmente antes de los años conflictivos en la región. No obstante estos esfuerzos, la historia de desarrollo y la manera cómo Huari se convirtió en el centro no sólo más grande del valle de Ayacucho, sino también el sitio con mayor influencia de los Andes Centrales sigue siendo poco esclarecido. Este conocimiento parcial obedece a varias razones, entre estas su enorme extensión y la falta de estudios interdisciplinarios a largo plazo. Investigaciones arqueológicas a pequeña escala y de corta duración tienen sus propias limitaciones, especialmente cuando se trata de un enorme sitio como Huari. En gran parte a partir de información recuperada del sector con arquitectura monumental de Huari, William Isbell $(1984,1997)$ ha presentado una larga secuencia de ocupación humana y durante la cual Huari logró su transformación hasta adquirir un carácter urbano. 
El objetivo de esta contribución es discutir el desarrollo de Huari en base a información nueva proveniente de la periferia de Huari. Se hace esto teniendo en consideración que una reconstrucción coherente del antiguo desarrollo de Huari tiene que incluir la zona periférica, especialmente considerando que el crecimiento del centro urbano posiblemente afectó, de una u otra forma, su periferia inmediata. Estamos convencidos que la formación de un extenso centro, como Huari, podrá ser comprendido sólo en relación a su inmediata periferia (Adams, 1966, p. 18). Con esto esperamos contribuir a la discusión acerca de este importante sitio y a la vez motivar futuras investigaciones en el mismo Huari y sus alrededores.

Previos estudios de reconocimiento realizados en los alrededores del centro urbano de Huari pusieron evidente la presencia de varios pequeños asentamientos rurales establecidos antes del Horizonte Medio (Menzel, 1964, p. 5-7; MacNeish, 1981; Benavides, 1976; Isbell, 1988, p. 175, 1997, p. 190; Schreiber, 2001, p. 81). Sin embargo, el envolvimiento de dichos asentamientos tempranos en el posterior surgimiento de Huari y la manera cómo el crecimiento de Huari impactó a dichos asentamientos no está del todo esclarecido. En la siguiente sección se hace una referencia general a los centros urbanos, la misma que sirve como punto de partida para discutir el caso específico del crecimiento Huari.

\section{LA APARICIÓN DE LOS CENTROS URBANOS}

El surgimiento de los centros urbanos representa un cambio significativo en relación a los tradicionales y antiguos patrones de existencia que tuvieron una orientación predominantemente rural (Chesson \& Goodale, 2014, p. 117). Por su misma naturaleza, los antiguos centros urbanos son extensos y congregaron una numerosa población (Cowgill, 2004, p. 527-528; Adams, 2012, p. 11; Smith 2014, p. 310-311), un gran número de los mismos sin relación de parentesco y cuya principal actividad fue otra que la agricultura. Los centros urbanos son también ocupados por una burocracia especializada en varias actividades vinculadas con la administración, negocios, producción de consumos, además de los dedicados a la actividad militar y religiosa. Finalmente, los residentes de los centros urbanos pertenecen a diferentes clases sociales y con vínculos a varios grupos étnicos de procedencia diversa.

La investigación arqueológica demuestra contundentemente que los antiguos centros urbanos surgieron sólo en determinadas regiones (Flannery, 1972, p. 400; Sinopoli, 1994), siendo los Andes Centrales uno de ellos (Makowski, 2008; Isbell, 2008; Stanish, 2001). Sin embargo, no está del todo determinado el por qué y las circunstancias bajo las cuáles los centros urbanos surgieron (Childe, 1951; Adams, 1966, 1972; Blanton, et al., 1993; Cowgill, 1997; Flannery \& Marcus, 2003, 2012; McIntosh 2005; Niessen, 2002; Wright \& Johnson, 1975; Wright, 1977). Así como se discute más adelante, una posibilidad que parece haber contribuido al establecimiento de los centros urbanos es la violencia. 
Huari es uno de los sitios arqueológicos más extensos de los Andes Centrales (Rowe, Collier \& Willey, 1950, p. 122; Lumbreras, 1960, p. 131, 2012; Isbell, 1997, p. 93; Schreiber, 2001, p. 81). El sitio se encuentra en el valle de Ayacucho de la sierra central del Perú, a una elevación que abarca entre los 2500 y 2900 m s. n. m. La inicial ocupación de Huari parece haberse dado alrededor de los años 100 a. C. Durante los siguientes 500 años, Huari continuó creciendo, alcanzando su transformación más acelerada aproximadamente alrededor del año 550 para finalmente convertirse en el centro urbano más extenso de todos los Andes Centrales durante los siguientes 300 años (Menzel, 1964; Rowe, 1963; Lumbreras, 1975; Isbell, 1984, 1988, 1997; Isbell \& Young-Sánchez, 2012; Scheriber, 1992, 2012)².

Varios investigadores sostienen que el cambio radical de Huari ocurrió paralelo al establecimiento de una autoridad política centralizada identificado como el Estado wari en el valle de Ayacucho (Menzel, 1964, p. 67; Isbell, 1987, p. 91; Isbell \& Cook, 1987; Isbell \& Knobloch, 2009; Cook, 2012; Schreiber, 1992). El Estado wari habría sido el organismo encargado de reorganizar las áreas inmediatas al centro urbano para luego iniciar con un ambicioso proyecto político nunca antes visto en los Andes Centrales, el establecimiento de un control político y económico sobre gran parte del actual territorio peruano, la misma que estaba controlada desde Huari, capital del Estado wari (Rowe, 1956, 1963, p. 14; Menzel, 1964, p. 68; Lumbreras, 1975, p. 115; Isbell \& Shreiber, 1978, p. 374; Schreiber, 1987, p. 93; 1992, p. 79, 93; 2001, p. 80; Stanish, 2001, p. 54). En las regiones recientemente incorporadas, el Estado wari logró construir una serie de centros intrusivos que exponen un estilo de arquitectura que es foránea (figuras $02 \& 03$ ) y que aparece asociada a un estilo de cerámica también foránea, con raíces en el valle de Ayacucho (Menzel, 1964). Estos centros, como Pikillaqta en Cusco (McEwan, 1991, 1996, 2005), han sido identificados como las capitales provinciales y por lo tanto fueron los nexos desde donde la administración wari logró ejercer control de las provincias (McEwan \& Williams, 2012; Nash \& Williams, 2009). Por último, las capitales provinciales habrían estado conectados por una red vial, grandes segmentos del mismo fueron posteriormente incorporados al camino real Inka (Hyslop, 1984).

Para comprender los cambios ocurridos en Huari es sumamente necesario conocer los cambios que posiblemente también ocurrieron en la periferia de Huari. Por lo tanto, en la siguiente sección, se hace una evaluación de lo que existió en el área antes del surgimiento de Huari y lo que se dio con el surgimiento de Huari. Como punto de referencia se tiene a un asentamiento rural que existió inmediatamente al oeste de Huari y que fue ocupado hasta finales del Periodo Intermedio Temprano.

2. Se ha sugerido que Huari, en el momento de su máximo apogeo, congregó una enorme población, la misma que habría oscilado entre los 10,000 y 70,000 habitantes (Isbell, 1997, p. 186). 


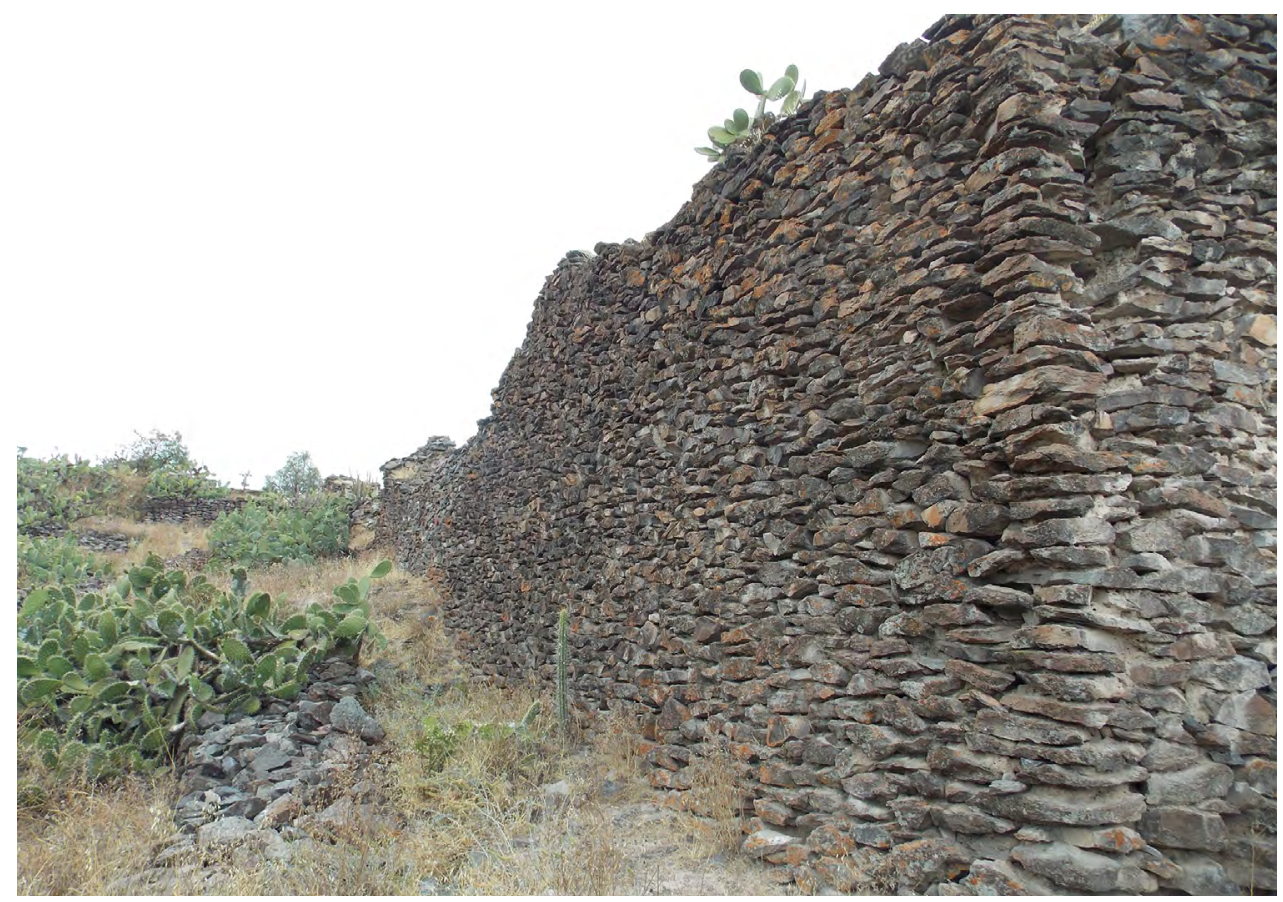

Figura 02. Arquitectura Wari: Estructura del área con arquitectura monumental de Huari

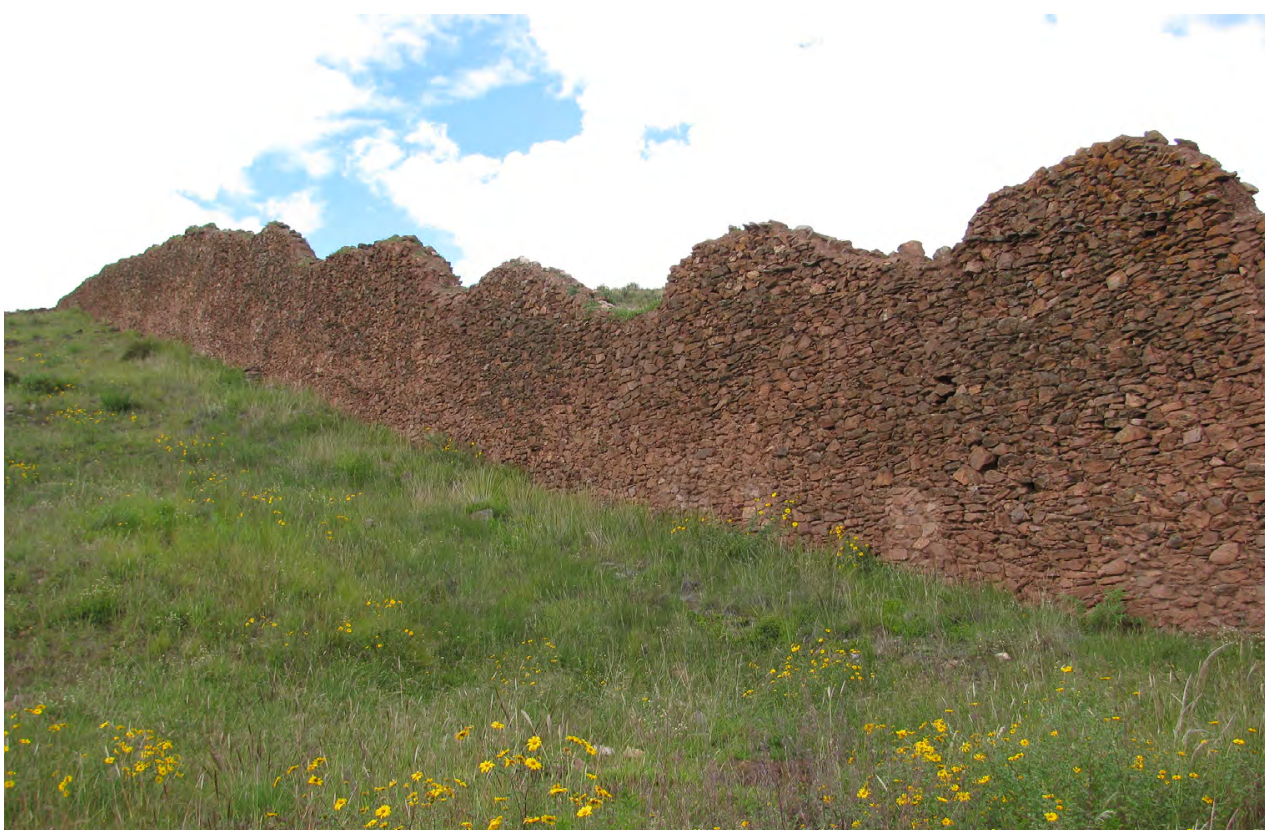

Figura 03. Arquitectura Wari: Estructura del sitio Wari de Pikillaqta del valle de Lucre, Cusco. 


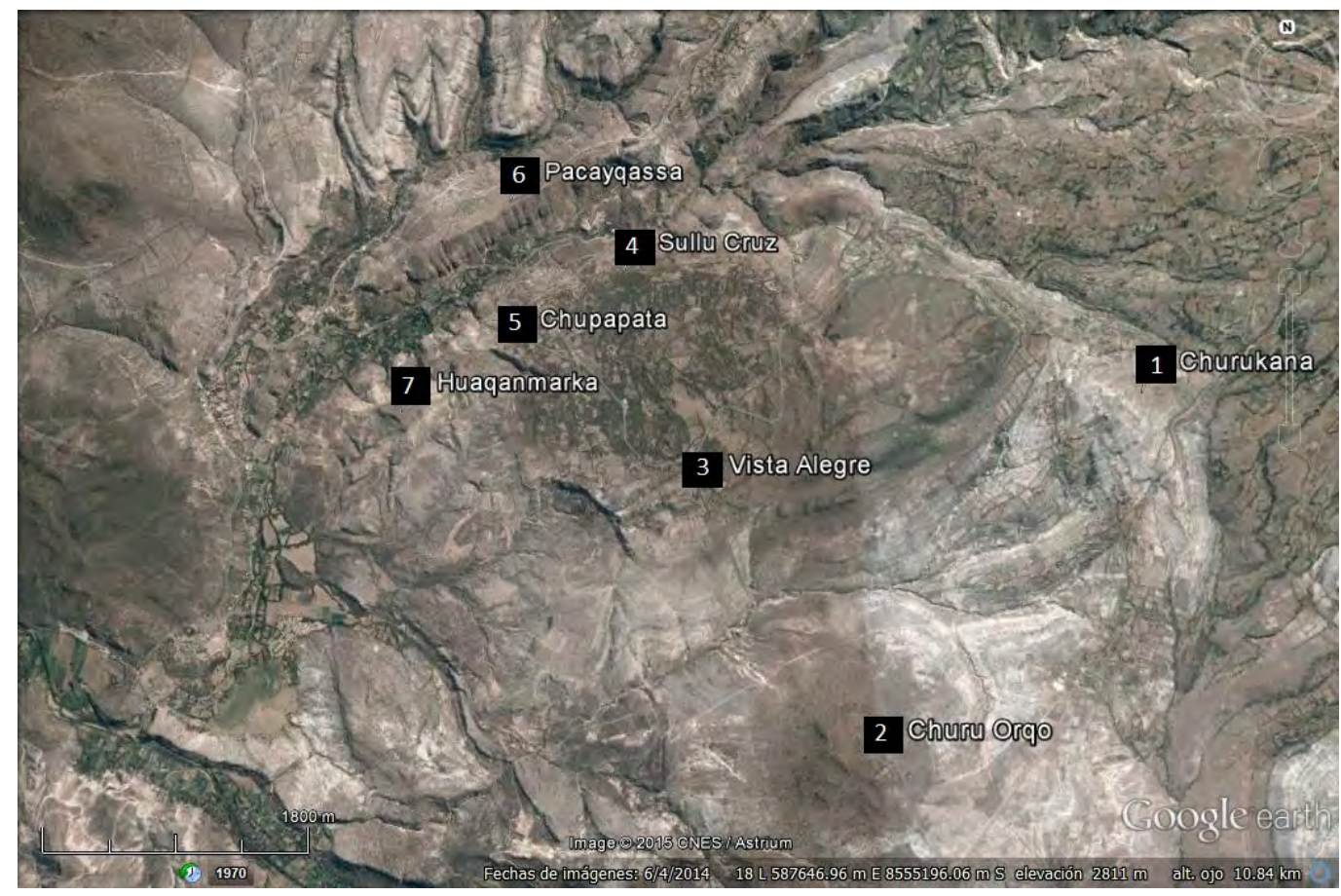

Figura 04. Mapa de ubicación de los asentamientos Huarpa ubicados en las inmediaciones de Huari.

\section{EL ASENTAMIENTO PRE-WARI DE HUAQANMARKA}

Estudios arqueológicos efectuados en la periferia de Huari han demostrado la presencia de varios pequeños asentamientos rurales (figura 04), establecidos y ocupados en su gran mayoría durante el Periodo Intermedio Temprano (Menzel, 1964; Isbell, 1997; Knobloch, 2013; Lumbreras, 2010), mientras que algunos incluso poco más antes (Isbell, 1997, p. 189). Estos asentamientos son: Churukana, ubicado sobre la cima de una colina al este de Huari (Menzel, 1964, p. 5; Isbell, 1997, p. 190), Vista Alegre, ubicado $4 \mathrm{~km}$ al oeste de Churukana y al sur del área con arquitectura monumental de Huari (Isbell, 1997; Knobloch, 2013), y Chupapata, ubicado inmediatamente al oeste del área con arquitectura monumental de Huari (Isbell, 1997: figura 6; Knobloch, 2013; Lumbreras, 2010: Lam. 34). Al extremo norte de Huari, en el sector de Sullu Cruz, Bennett (1953) hizo una pequeña excavación y expuso cerámica huarpa y que indica la existencia de una ocupación pre-wari (Menzel, 1964, p. 7; Lumbreras, 2010, p. 36). Además de estos cuatro asentamientos, existen otros sitios similares; uno estaba ubicado en la cima del cerro Churo Orqo ubicado al sur de Vista Alegre, otro al norte de Huari (al este del poblado contemporáneo de Pacaycasa), y un tercero inmediatamente al oeste de Chupa Pata - este último es Huaqanmarka. 


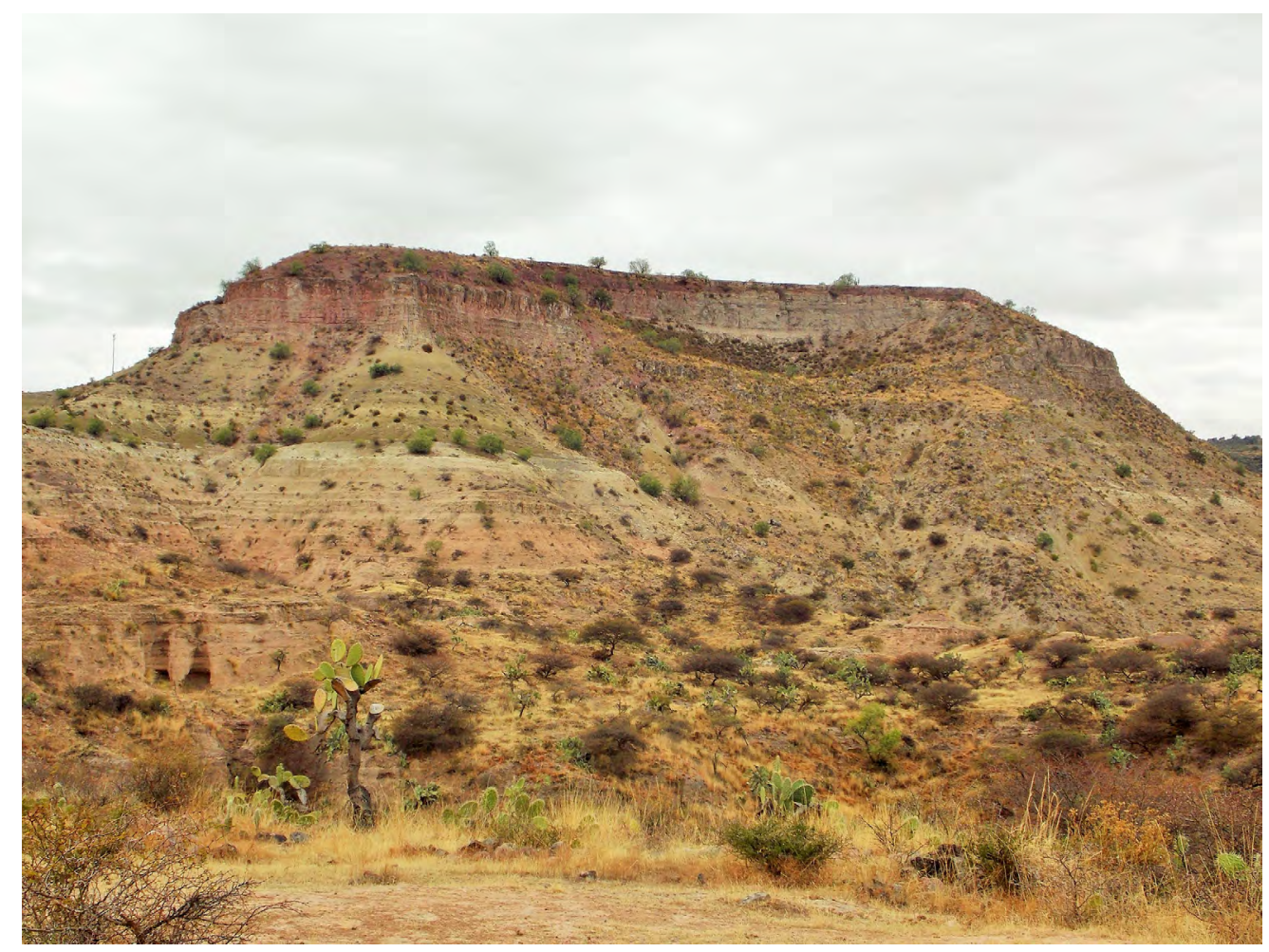

Figura 05. Sitio Huarpa de Huaqanmarka visto desde su lado oeste.

Huaqanmarka está sobre la meseta de una colina figura 5), que vista desde su lado oeste tiene algo de parecido al sitio de Cerro Baúl, un enclave wari en el valle de Moquegua (Williams, 2001; Williams \& Nash, 2002; McEwan \& Williams, 2012). La meseta de Huaqanmarka está cortada en su totalidad por una pendiente de caída vertical, lo que hace del lugar poco accesible. En la actualidad, existe sólo un acceso accidentado por el lado norte de la meseta. Considerando que la meseta es de difícil acceso y sin una fuente segura de agua, puede haber poca duda que su ocupación significó superar obstáculos mayores. Sin embargo, la cima del sitio ofrece una buena visibilidad, sobre todo hacia la parte oeste de Huari. Por lo tanto, existe la posibilidad que el lugar tal vez fue elegido por sus particularidades defensivas, especialmente su difícil acceso. Con el principal objetivo de obtener información que permita conocer la antigua historia de ocupación humana de la meseta, una excavación arqueológica se llevó adelante en el sitio (Valdez \& Valdez, 2016, 2017). Dicha información indica que una considerable población ocupó el lugar antes del Horizonte Medio.

La ocupación más temprana de la meseta, establecida sobre suelo estéril, está representada por una estructura relativamente larga, de forma rectangular y cuyos muros habían sido establecidos con bloques de arcilla, piedras del campo, unidas con 


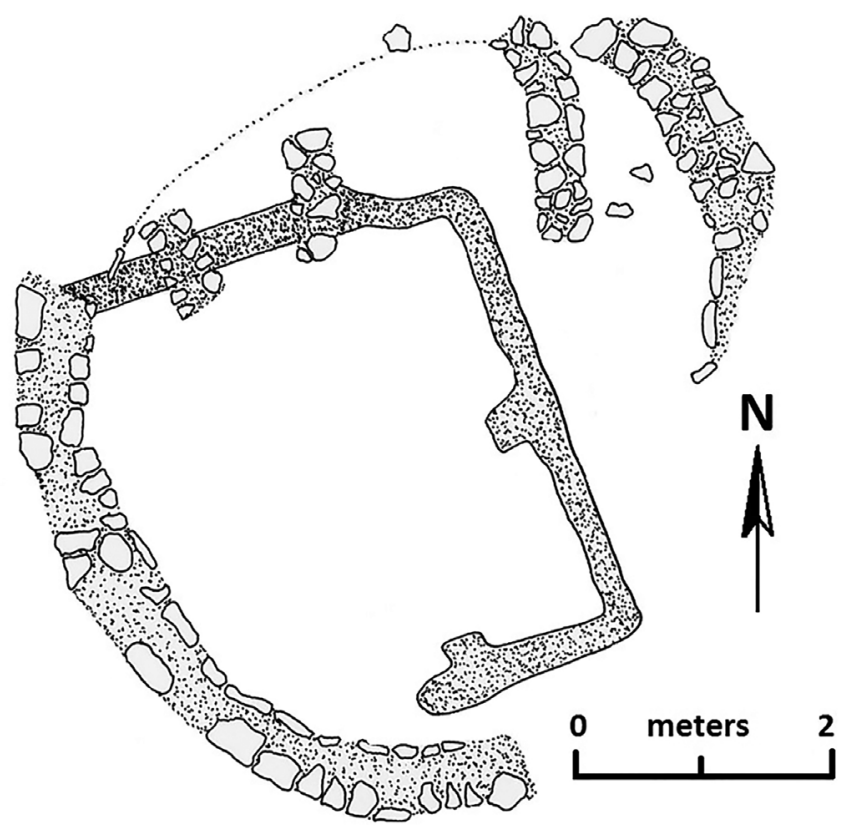

Figura 06. La antigua estructura rectangular expuesta en Huaqanmarka.

argamasa de barro (figura 06). Construcciones posteriores habían sido levantadas encima de la vieja estructura, proceso durante la cual segmentos de los muros antiguos fueron demolidos. Entre los varios restos arqueológicos asociados a la antigua estructura sobresalen los fragmentos de cerámica. Dichos restos son de particular importancia para determinar la cronología relativa de la inicial ocupación de la meseta, especialmente considerando que a la fecha no se cuenta con fechados absolutos.

Los fragmentos de cerámica asociados a la antigua estructura exhiben una superficie áspera y donde son visibles las líneas producidas durante el proceso de manufactura de las vajillas. La pasta es un beige oscuro, compacto, y donde son visibles los desgrasantes. Además, en ambas superficies hay una abundante presencia de pequeñas partículas de mica. Algunos de los fragmentos presentan diseños consistentes de círculos impresos sobre una superficie húmeda, los mismos que son típicos de la cerámica manufactura durante las fases tardías del Horizonte Temprano (figura 07). Sin embargo, la mayoría de los fragmentos muestran un acabado bastante simple y denota una función netamente domestica del asentamiento. Efectivamente, varias formas de vasijas utilitarias han sido determinadas, la misma que incluye ollas sin cuello y jarras de cuello angosto (figura 08). Estas formas, en particular las jarras, continuaron siendo manufacturadas al tiempo que nuevas estructuras fueron construidos en la meseta. 


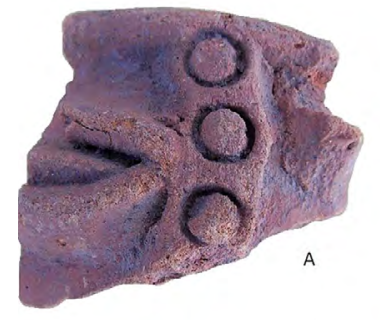

0 $\mathrm{cm}$

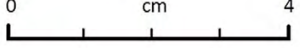

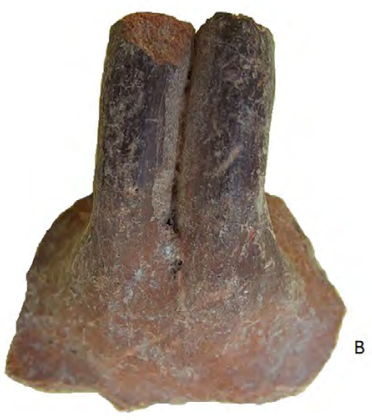

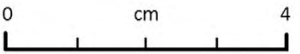

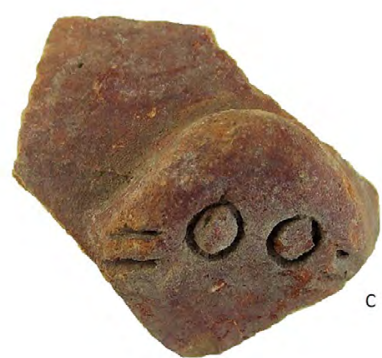

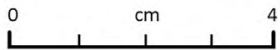

Figura 07. Cerámica hallada en asociación a la estructura rectangular de Huaqanmarka.
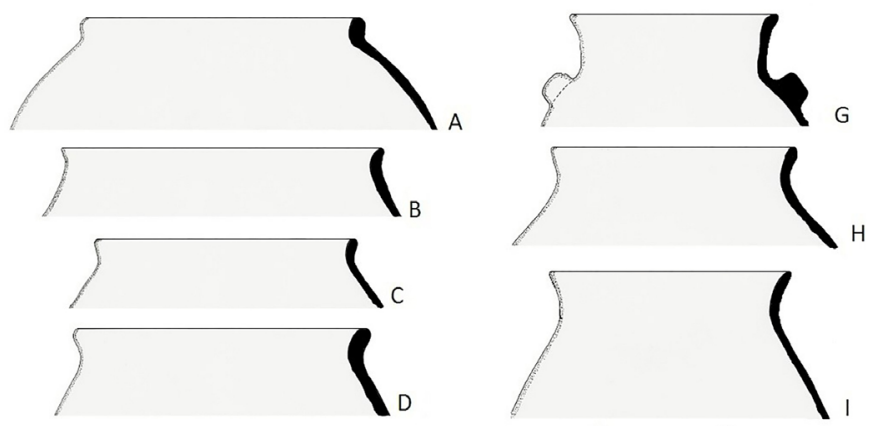

$0 \mathrm{~cm} 10$
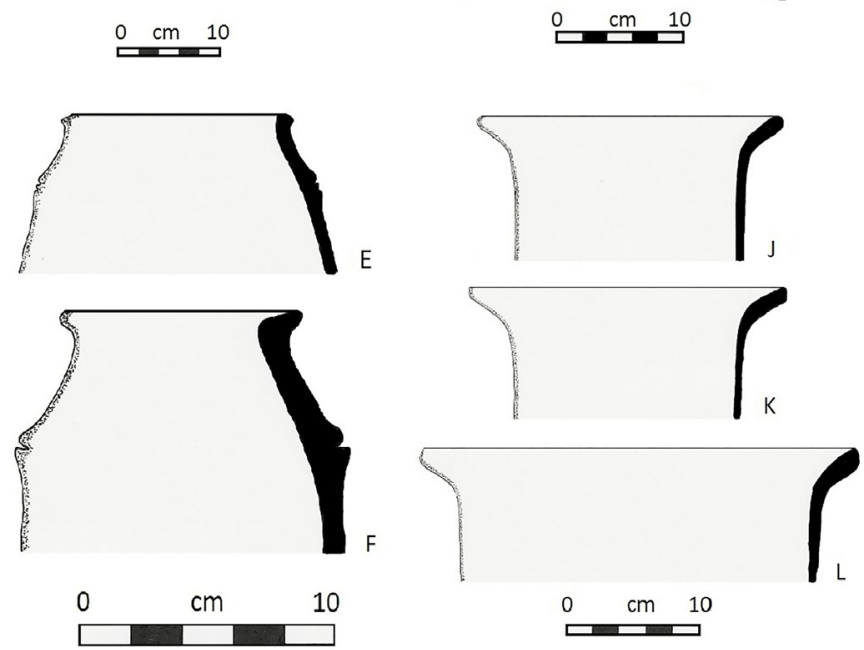

\begin{tabular}{cc}
$\mathrm{cm} \quad 10$ \\
\hline
\end{tabular}

Figura 08. Formas de las vasijas halladas en asociación a la antigua estructura rectangular 
Antes a la ocupación representada por la estructura rectangular, la meseta fue ocasionalmente visitada, tal como indica la presencia de algunos fragmentos de cerámica Wichqana, representativo de las fases iniciales del Horizonte Temprano. Sin embargo, dichos fragmentos son raros y sugiere que en la meseta no había una ocupación permanente. Isbell (1997, p. 190) asegura que en Churukana había una ocupación asociada con la cerámica Wichqana. Considerando que la distancia entre Churukana y Huaqanmarka es corta y por lo tanto transitable en menos de una hora, parece probable que los antiguos residentes de Churukana visitaron la cima de Huaqanmarka.

Entretanto, el distintivo estilo de cerámica Caja, asociado con las fases finales del Horizonte Temprano (Lumbreras, 1959, p. 75; 1974, p. 136), está ausente en Huaqanmarka. Esto indica que a finales del Horizonte Temprano todavía no existió una población permanente en el lugar, o que sus pobladores simplemente no utilizaron la variedad de cerámica Caja.

El trabajo de investigación realizado en Huaqanmarka demuestra que una mayor ocupación del lugar ocurrió al tiempo que se construyeron estructuras circulares, que sustituyeron a la estructura rectangular (figura 09). Desafortunadamente, las actividades agrícolas contemporáneas llegaron a destruir muchas de las estructuras, en algunas instancias incluso borrándolos del todo. Como resultado, se hace difícil determinar con certeza la asociación de los artefactos con estructuras específicas. No obstante estas limitaciones, el trabajo en Huaqanmarka permitió determinar tres estructuras circulares parcialmente destruidas. En asociación a estas estructuras ocurren algunos fragmentos de cerámica que también ocurren asociados a la estructura antigua, como también fragmentos que sólo fueron notados en asociación a las estructuras circulares.

En asociación a las estructuras circulares ocurre una mayor cantidad de fragmentos de cerámica y sugiere una densa ocupación del asentamiento. Los fragmentos de cerámica diagnóstica con mayor

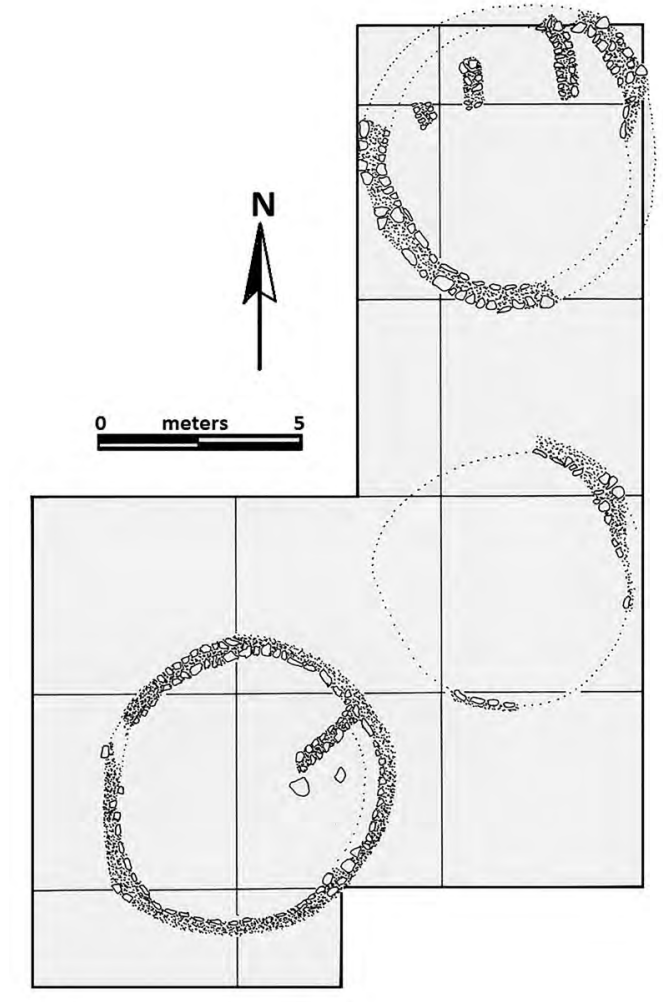

Figura 09. Estructuras de planta circular expuestas en Huaqanmarka. 
ocurrencia son aquellos asociados con el Periodo Intermedio Temprano (Menzel, 1964; Lumbreras, 1974, 1975; Valdez, 1996, 1997). Este incluye, primero, el distintivo estilo Kumun Senqa (figura 10a), caracterizado por una superficie de color rojo oscuro y paredes gruesas y, segundo, el estilo huarpa Negro sobre Blanco (figura 10b), caracterizado por una superficie blanca y paredes gruesas. Ambos estilos corresponden a formas de vasijas de tamaño grande, cuello angosto, cuerpo esférico, y base generalmente cónica (Lumbreras, 1974, p. 136-137; Schreiber, 1992, p. 84; Knobloch, 2013). Debido a sus tamaños grandes y una base predominantemente cónica, es posible que estas fueron utilizadas para depositar granos y bebidas, tal vez incluido la chicha. Estos dos estilos de cerámica muestran una superficie por lo general áspera, aunque ligeramente pulidos, especialmente en sus lados exteriores, mientras que la superficie interna fue pulida sólo alrededor del cuello. Otras vasijas de menor tamaño, particularmente en el estilo Huarpa Negro sobre Blanco también ocurren. Tal como se anotó líneas adelante, formas de vasijas observadas inicialmente en asociación a la estructura rectangular ocurren al lado de los estilos aquí mencionados, indicando una continuación cultural.

Además de la cerámica, en asociación a las estructuras circulares resalta la presencia de la parte activa de los batanes (tunay) e indica que las actividades desarrolladas en las estructuras circulares incluyó el procesamiento de los alimentos, posiblemente granos. Del mismo modo resalta la ocurrencia de las ruecas de hilar (piruros) hechos en cerámica, indicando que el hilado y la actividad textil fueron igualmente importantes. Puesto en conjunto, la evidencia aquí presentada sugiere que la cima de Huaqanmarka congregó una numerosa población, pero la ocupación fue de carácter doméstico.

Junto a la cerámica huarpa perteneciente al Periodo Intermedio Temprano también ocurren otras piezas que muestran una decoración en el estilo Huarpa Negro sobre Blanco, pero que exhiben un acabado más sofisticado. Estas vajillas son de pared bastante delgada, con pasta fina, superficie con mejor tratamiento y suave, con un baño de engobe de color marrón oscuro y blanco. Estos son atributos nuevos para la cerámica de esta región. Estas vajillas por lo general consisten de copas, tazas profundas y botellas (figura 11). Lo más resaltante de estas vajillas es que son las primeras de todo el valle de Ayacucho en representar diseños foráneos (figura 12), en este caso provenientes de la costa sur - diseños Nasca tardío. La presencia de dichos motivos foráneos indica que los lazos de interacción entre los habitantes del valle de Ayacucho y los de la costa sur fuera fluido a finales del Periodo Intermedio Temprano (Menzel, 1964, p. 7; Knobloch, 1991, p. 248).

Los motivos nasca tardío representados en la cerámica del valle de Ayacucho incluye uno que parece ser la forma estilizada de las vainas del frijol (Proulx, 2006, p. 164), además de otro inicialmente identificado por Proulx (2006, p. 186) como el "bastón con flores." Este último fue también identificado por Menzel (1964, p. 9; 


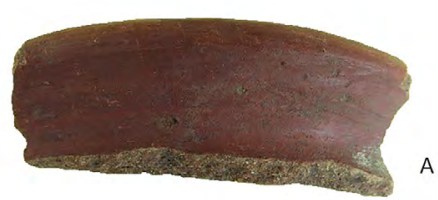

$\stackrel{\mathrm{cm},}{0}, \quad 5$
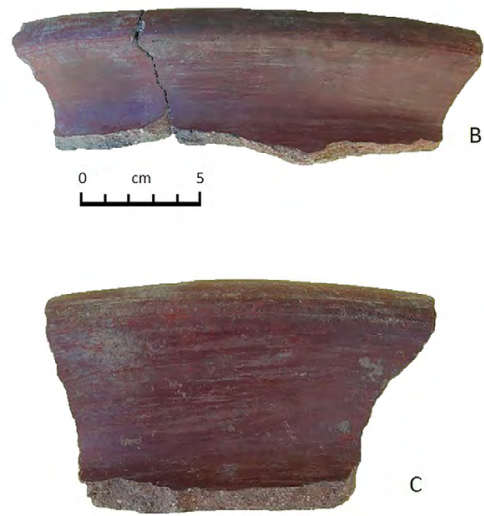

$\stackrel{\mathrm{cm},}{0}+5$
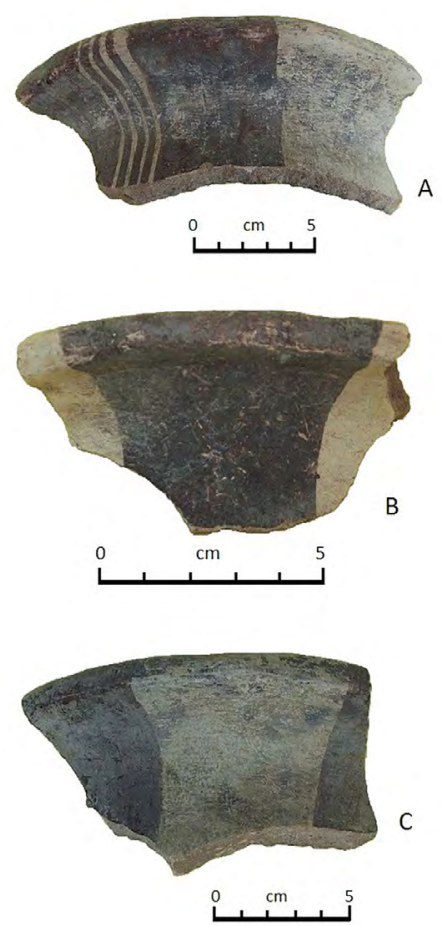

Figura 10. Fragmentos de la izquierda: cerámica en el estilo Kumun Senqa hallada en asociación a la estructura circular de Huaqanmarka; fragmentos de la derecha: cerámica en el estilo Huarpa Negro/Blanco hallada en asociación a la estructura circular de Huaqanmarka.
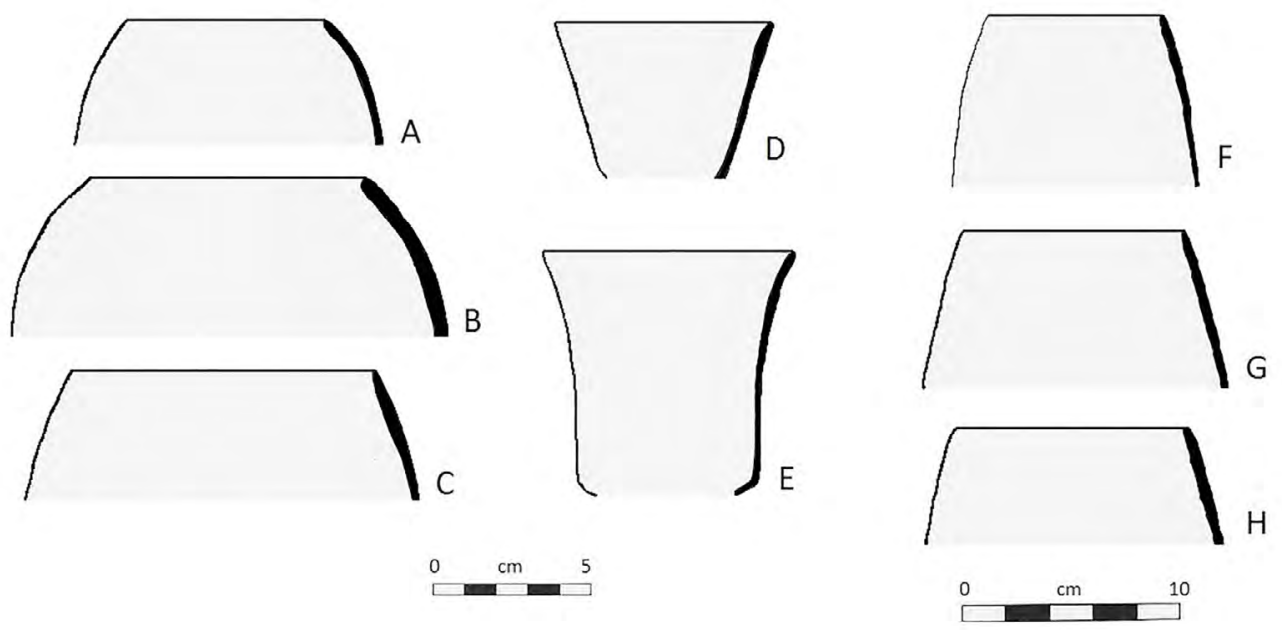

Figura 11. Formas de las vajillas en el estilo Huarpa Negro/Blanco con diseños Nasca tardío 

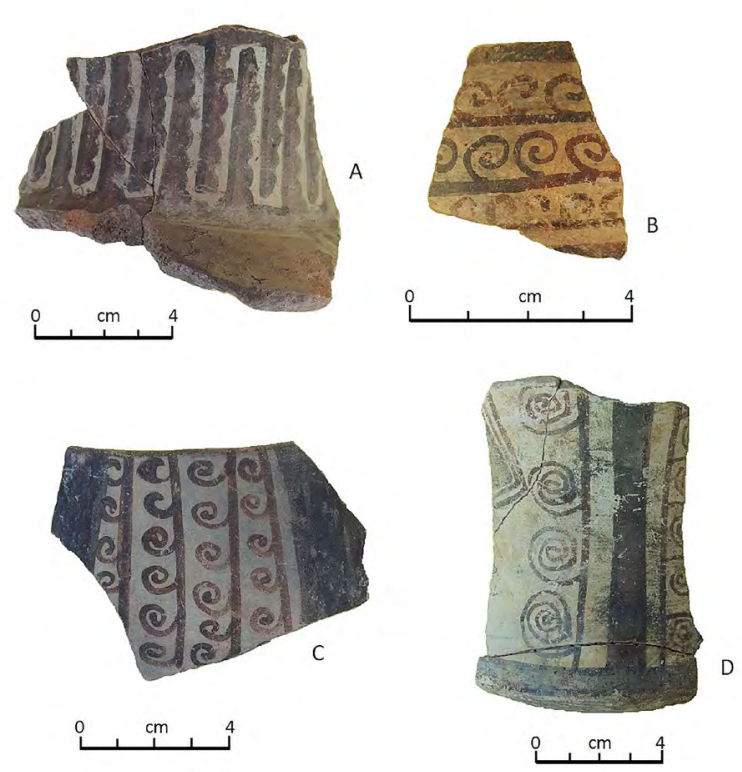

Figura 12. Vajillas del estilo Huarpa Negro/Blanco exhibiendo motivos Nasca tardío.

Bennett, 1953: Plate 12; Knobloch, 2012: figura 93) como "espirales negros adheridos a barras." Estos dos diseños son frecuentes en vajillas pertenecientes a la fase Nasca 7 (Proulx, 1994, p. 95). Así como fue inicialmente anotado por Menzel (1964, p. 7), además de los motivos y los nuevos colores, la forma de las vajillas guardan mucha similitud con las formas de la cerámica nasca tardío. En tanto que las vajillas decoradas con motivos nasca tardío también exhiben una obvia sofisticación tecnológica (Lumbreras, 1975, p. 116; Knobloch, 2012, p. 125; Schreiber 2012, p. 38), la misma que es definitivamente distinto de las vajillas Huarpa, existe la posibilidad que las nuevas formas de vajillas producidas en el valle de Ayacucho tal vez fueron manufacturadas por manos nasca. Más adelante volvemos a discutir este asunto.

Mientras que la investigación arqueológica realizada en Huaqanmarka permite conocer que existió una ocupación bastante representativa durante el Periodo Intermedio Temprano, los estilos de cerámica que marcan el final de dicho periodo en el valle de Ayacucho, caso Cruz Pata y Okros (Lumbreras, 1974, p. 138; 1980, p. 24; Knobloch, 1991, p. 248; 2012: Figure 94; Menzel, 1964, p. 17; Schreiber, 1992, p. 86), no fueron encontrados en el sitio. Dicha ausencia sugiere que Huaqanmarka posiblemente fue abandonado corto tiempo después que los motivos nasca iniciaron a ser representados en el valle de Ayacucho y obviamente ante que los estilos Cruz Pata y Okros empezaron a ser manufacturados. De este modo, Huaqanmarka podría haber quedado despoblado; sin embargo, ocasionalmente el lugar fue visitado tal como sugiere la ocurrencia de algunos fragmentos de cerámica pertenecientes al Horizonte Medio. 
De la información hasta aquí presentada, la cerámica hallada en Huaqanmarka provee de información concreta en relación a la antigua ocupación humana del lugar. Dicha ocupación se dio específicamente durante el periodo anterior al Horizonte Medio y antes del establecimiento del Estado wari. La evidencia del que se dispone también indica que la ocupación de Huaqanmarka fue de una orientación rural. Huaqanmarka fue abandonado alrededor de las fases finales del Periodo Intermedio Temprano, hecho que parece haber dado paralelo al abandono de otros asentamientos contemporáneos y adyacentes a Huaqanmarka. Entretanto, otros asentamientos -como el mismo Huari-empezaron a crecer. En la siguiente sección pasamos a discutir este tema.

\section{NUCLEACIÓN POBLACIONAL EN EL VALLE DE AYACUCHO}

Antes de los trabajos de investigación arqueológica realizados en la cima de Huaqanmarka ya se conocía que varios asentamientos huarpa que existieron en las inmediaciones de Huari habían sido abandonados al tiempo que Huari inició con un proceso de transformación (MacNeish, 1981; Benavides, 1976; Pérez Calderón, 2001). Por ejemplo, en base a evidencias de superficie, Menzel (1964, p. 5) observó en Churukana una abundante ocurrencia de cerámica huarpa perteneciente al Periodo Intermedio Temprano, mientras que evidencias pertenecientes al Horizonte Medio ocurrían sólo ocasionalmente. En base a dicha observación, Menzel sostuvo que Churukana habría quedado despoblado al final del Periodo Intermedio Temprano. Excavaciones de prueba realizados en Churukana han corroborado a lo inicialmente sugerido por Menzel (Isbell, 1997, p. 193; Lumbreras, 2010, p. 37).

Una reciente inspección de Churo Orqo, un segundo asentamiento huarpa ubicado en la cima de la colina situada inmediatamente al sur de Huari, reveló la ocurrencia de cerámica huarpa y ausencia de evidencias pertenecientes al Horizonte Medio. Esta evidencia indica que Churo Orqo parece también haber sido despoblado paralelo a Churukana. En Vista Alegre, un tercer asentamiento huarpa situado entre Churo Orqo y el área con arquitectura monumental de Huari (Lumbreras, 2010, p. 146) también hay una abundante ocurrencia de cerámica huarpa (Isbell, 1997, p. 192; Knobloch, 1991, p. 248; Menzel, 1964, p. 5-7; Schreiber, 2001, p. 81), mientras cerámica del Horizonte Medio es menos representativo. Isbell (1997) postula que Vista Alegre fue despoblado simultáneo a Churukana. Por lo tanto, el abandono al parecer paralelo de varios asentamientos huarpa a finales del Periodo Intermedio Temprano es de particular importancia, en tanto que - en base a la información del que se dispone - parece coincidir con el crecimiento de algunos asentamientos. Esta modificación en los patrones de asentamiento que predominó por varias generaciones es de particular interés en tanto que este proceso se produjo en todo el valle de Ayacucho (MacNeish, 1981, p. 224, Figuras 8.11 \& 8.12) y favoreció en eventual crecimiento de centros como el mismo Huari. 
Paralelo al abandono de los asentamientos huarpa, como Huaqanmarka, otros asentamientos empezaron a crecer. Para el área de Huari, Chupapata parece que fue uno de tales asentamientos (Lumbreras, 2010, p. 37, 146; Isbell, 1997, p. 194; Knobloch, 2013). Sullu Cruz, otro asentamiento ocupado en tiempos Huarpa y ubicado a corta distancia al este de Chupapata, posiblemente también permaneció ocupado y tal vez también haya empezado a crecer. Aunque está por determinarse la forma cómo y las circunstancias bajo las cuales estos asentamientos previamente pequeños hayan empezado a crecer, una posibilidad por considerarse es la llegada de una numerosa población procedente de los asentamientos que empezaron a ser abandonados, como Churukana y Huaqanmarka, por ejemplo. Si esta observación tiene alguna validez, asentamientos próximos como Sullu Cruz y Chupapata no sólo se habrían transformado en asentamientos mayores en relativamente corto tiempo, sino también llegaron a fusionarse, convirtiéndose de este modo en un sólo asentamiento, pero definitivamente mucho más extenso de lo que fueron originalmente (Isbell \& Schreiber, 1978, p. 383).

Por lo tanto, todo parece indicar que Huari fue establecido sobre la base de dos asentamientos huarpa que existieron en el lugar con anterioridad (Schreiber, 2001, p. 81). Del mismo modo, se hace aparente que el crecimiento de Huari está estrechamente ligado al abandono de varios asentamientos rurales huarpa que hasta entonces prevalecieron en la región. En otras palabras, la eventual transformación de Huari en el asentamiento más extenso de todos los Andes Centrales parece mantener una fuerte conexión con la masiva migración desde los centros rurales huarpa que fueron abandonados. Más adelante retornamos a discutir este proceso. De este modo, la historia del crecimiento de Huari es similar al del antiguo Uruk en el sur de Mesopotamia (Adams, 2012, p. 11; Mcintosh, 2005, p. 64; Nissen, 2002).

Desde las primeras observaciones hechas por Rowe, Collier y Willey (1950); Rowe (1963); Lumbreras (1960); Menzel (1964); Isbell (1988); Isbell \& Schreiber (1978); Schreiber (2001), los especialistas reconocen la enorme extensión de Huari. Sin embargo, interrogantes con respecto al cómo y bajo qué circunstancias Huari logró alcanzar dicha transformación siguen siendo difíciles de responder, particularmente teniendo en consideración lo que en la actualidad se conoce del mismo Huari. Existen algunas evidencias que permiten sostener que Huari fue el beneficiario del masivo abandono de los varios asentamientos rurales huarpa que hasta entonces existieron en la región. Esto abre la posibilidad que Huari tal vez jugó rol determinante para el abandono de tales asentamientos. En la siguiente sección procedemos a discutir estas posibilidades.

\section{CONFLICTO Y NUCLEACIÓN}

Los asentamientos humanos se establecen y crecen - por lo general- durante un periodo relativamente largo. Los asentamientos pre-urbanos en particular, caso 
Huaqanmarka, desde el momento que fueron establecidos fueron ocupados continuamente por varios cientos de años. Dicha larga historia de ocupación humana demuestra que estos centros pre-urbanos fueron viables; de lo contrario, dichos asentamientos hubieran quedado despoblados después de una corta ocupación. En consecuencia, asentamientos como Huaqanmarka fueron lugares donde no sólo nacieron los ancestros, sino también constituyeron los lugares donde fueron depositados los restos de las cabezas de los linajes.

Si bien todo asentamiento tiene una vida de ocupación, merece preguntar por qué y bajo qué circunstancias los asentamientos que fueron ocupados de manera sucesiva por muchas generaciones tuvieron que ser finalmente abandonados. En definitiva, los antiguos asentamientos posiblemente llegaron a ser despoblados por muchas razones. Por ejemplo, esto puede ser su proximidad a tierras agrícolamente importantes. Sin embargo, una evaluación del carácter de los nuevos asentamientos que surgieron en la misma región parece tener el potencial de ayudar a explicar las interrogantes indicadas líneas adelante. Partiendo de esta premisa es como pretendemos abordar el tema concerniente al abandono de Huaqanmarka y otros asentamientos inmediatos a éste.

Así como se mencionó brevemente en la sección anterior, al tiempo que varios asentamientos rurales como Huaqanmarka -y otros contemporáneos a éstequedaron despoblados, otros asentamientos ubicados en las inmediaciones no sólo continuaron siendo ocupados, sino también empezaron a crecer. Existe una buena base literaria que discute casos similares, y en general se sostiene que la preferencia por pocos, pero más extensos asentamientos que los anteriores obedece a la necesidad por la defensa (LeBlanc, 2006, p. 443-445; Flannery \& Marcus, 2012, p. 451-472; Haymes, 1983, p. 398; Elliott, 2005, p. 299; Schreiber, 1999, p. 168). Dicha necesidad surge debido a las nuevas condiciones sociales que son violentas. La lógica detrás de este razonamiento es que los asentamientos más extensos, que posiblemente también son mejor protegidos por disponer de sistemas defensivos, ofrecen mayor seguridad. En contraste, los asentamientos pequeños por lo general se encuentran no sólo dispersos, sino también carecen de sistemas defensivos; como resultado, estos asentamientos son más vulnerables a una posible ofensiva militar enemiga (Roscoe, 2008). Además, los investigadores sostienen que la violencia a menudo resulta en el establecimiento de asentamientos defensivos, como son las fortificaciones (Roscoe, 2008, p. 513-515; Trigger, 1990, p. 121-122; Valdez, 2014). En efecto, en la opinión de Allen y Arkush (2006, p. 7), las fortificaciones son los indicadores más obvios del conflicto.

A la fecha, resalta que ningún asentamiento del valle de Ayacucho contemporáneo a Huaqanmarka haya sido satisfactoriamente identificado como una fortificación (Isbell, 1987). Sin embargo, es importante enfatizar que un buen número de 
asentamientos mencionados en esta discusión, incluido Huaqanmarka, sí habían sido edificados en lugares identificables como defensivos por estar en las colinas elevadas. Dichos lugares proveen por ejemplo de una amplia visibilidad, aspecto este que hace de dichos lugares ventajosos y estratégicos en tiempos de conflicto. El sitio de Ñawinpukyo también había sido establecido sobre la cima de una colina (Lumbreras, 1975, p. 105). Por lo tanto, es posible que algún tipo de conflicto, posiblemente entre asentamientos vecinos, ya existió en el valle de Ayacucho durante el Periodo Intermedio Temprano.

Confirmando en parte que la situación social en el valle de Ayacucho a finales del Periodo Intermedio Temprano no fue del todo pacífica, existen evidencias arqueológicas que precisamente apuntan en dicha dirección. Por ejemplo, partes de cuerpos humanos, identificados como trofeos han sido recuperados del sitio de Ñawimpukyo de contextos huarpa (Finucane, 2008, p. 82-83). Del mismo modo, esqueletos humanos con lesiones, al parecer sostenidos en combates frontales, han sido recuperados del sitio de Conchopata también de contextos huarpa (Tung, 2012, p. 103). Toda esta información nueva, aunque todavía limitado, viene dejando en claro que antes del surgimiento de Huari el contexto social en el valle de Ayacucho ya fue violento. Durante el Horizonte Medio, el conflicto parece que se intensificó; esta vez no sólo están las lesiones observables en los huesos, sino también la iconografía presenta imágenes de violencia (Tung, 2012, p. 99, 105, 106; Tung \& Knudson, 2011, p. 253). De lo expuesto, la posibilidad que la violencia fue la principal razón para el abandono de los asentamientos huarpa se incrementa. En una situación de violencia es de anticipar que los residentes de los asentamientos menos protegidos se hayan visto en la necesidad de tomar refugio en asentamientos mejor protegidos.

Una consecuencia inmediata de una mayor concentración de la población en lugares determinados es que un territorio relativamente extenso quede despoblado o parcialmente despoblado (Flannery \& Marcus, 2003, p. 11803; 2012, p. 455; Arkush \& Stanish, 2005, p. 15; LeBlanc, 2006, p. 443; Redmond \& Spencer, 2006, p. 342-343). Para el caso del valle de Ayacucho, el inicial trabajo dirigido por MacNeish reveló en primera instancia un decrecimiento considerable del número de asentamientos entre el final del Periodo Intermedio Temprano y el inicio del Horizonte Medio. Al mismo tiempo, para el área entre Huari y Conchopata, y con la posible excepción del sitio de Totorilla (Menzel, 1964, p. 6), no existen otros asentamientos correspondientes a las fases iniciales del desarrollo de Wari; esto sugiere que dicho territorio quedó abandonado o parcialmente despoblado. Importante es anotar, además, que Totorilla parece representar una ocupación corta y que posiblemente fue absorbido por Conchopata o Huari, dejando así la zona intermedia entre estos dos asentamientos en estado vacante. Esto sugiere que las relaciones entre Huari y Conchopata no fuera necesariamente amigable. 
En la opinión de Kent Flannery y Joyce Marcus (2012, p. 374), la concentración de una numerosa población en un centro específico a menudo resulta en la aparición de asentamientos similares en regiones vecinas. La razón para tal ocurrencia es el interés de mantener autonomía y distancia de potenciales agresores. Flannery y Marcus (2012, p. 459) plantean que en una situación de conflicto, la mejor alternativa para mantener la autonomía es precisamente hacerse grande. Esto es lo que ocurrió, por ejemplo, en las regiones vecinas al valle de Oaxaca donde se estableció Monte Albán (Blanton et al., 1993, p. 70). Para el caso específico del valle de Ayacucho, se plantea que en Conchopata, un asentamiento wari ubicado en el mismo valle de Ayacucho y a sólo 25 kms al sur de Huari (Pérez Calderón, 2012; Ochatoma \& Cabrera, 1999), también se dio un proceso similar al de Huari. En este caso varios asentamientos huarpa también habían quedado despoblados, mientras una masiva concentración parece haberse dado en Conchopata (Lumbreras, 2010, p. 37). Ñawinpukyo, un asentamiento vecino a Conchopata y ubicado sobre la cima de una colina (Lumbreras, 1975, p. 105; Leoni, 2006, 2010), parece haber quedado parcialmente despoblado (Lumbreras, 2010, p. 37) cuando sus residentes decidieron reubicarse en otro lugar, al parecer en Conchopata. Isbell (1997, p. 195) sostiene que durante las fases iniciales del desarrollo de Huari, Conchopata y Huari posiblemente entraron en competencia. Dicha supuesta competencia pudo haber surgido, por un lado, del deseo por parte de ambos asentamientos de mantener autonomía y, por otro lado, por ejercer control sobre poblados vecinos.

De este modo, la inicial evidencia arqueológica proveniente de Huaqanmarka sugiere que los asentamientos huarpa fueron estables por mucho tiempo. Sin embargo, siguiendo la interacción establecida con la costa sur la situación social en el valle de Ayacucho cambió considerablemente, tal como indica la reducción del número de los asentamientos y el incremento de algunos. Aquí es oportuno enfatizar que la interacción con otros pueblos tiene el potencial, entre otros, de crear la diferenciación social (Flannery \& Marcus, 2012, p. 197). Como en el caso discutido por Leach (1990, p. 219-222), por ejemplo, existe la posibilidad que algunos pobladores del valle de Ayacucho tal vez lograron elevar su prestigio y así iniciar a perpetuar sus posiciones privilegiadas. Es posible que dicho interés resultó ser en un principio competitivo y luego violento. El acceso a productos e ideas foráneas pudieron haber sido algunas de las razones que llegó a desequilibrar a una cultura que mucho tiempo parece haber sido relativamente conservadora. Líneas más adelante volvemos a tocar este tema.

En una situación de conflicto, los líderes de asentamientos en competencia, como Huari y Conchopata, probablemente participaron activamente en atraer a un mayor número de seguidores hacia sus respectivos centros (Isbell, 1991, p. 309). Dichos líderes posiblemente fueron conscientes que la única opción para mantener la autonomía fue hacerse grande. Sin embargo, para atraer de manera efectiva a nuevos seguidores 
centros como Huari y Conchopata tenían que ser bien protegidos para así garantizar la seguridad de sus residentes. Lumbreras (2010, p. 38) sostiene que Huari fue un asentamiento bien protegido, igual que Teotihuacan (Millon, 1973; Adams, 1977, p. 192) y la ciudad de Uruk (Pallock, 1999, p. 72; Flannery \& Marcus, 2012, p. 459). En efecto, por su lado norte Huari es impenetrable en tanto que está protegido por una profunda quebrada (figura 13) que sirve como una barrera natural. Por su lado oeste también está protegido por una pendiente de difícil acceso, mientras que por sus lados este y sur, siguiendo a Lumbreras, el sitio estaba protegido por grandes muros.

Así como se dio con Uruk (Adams, 1972, p. 21; 2012, p. 11; Flannery \& Marcus, 2012, p. 458-459), es posible que los asentamientos huarpa que se vieron vulnerables a ataques militares optaron por abandonar sus comunidades por la seguridad que ofrecían las murallas de Huari, por ejemplo. La manera como Huari creció, de manera desordenada y sin seguir plan alguno (Lumbreras, 1986, p. 57), parece indicar no sólo que los poblados rurales huarpa fueron abandonados dentro de un tiempo relativamente corto, sino también que Huari creció de manera bastante rápida (figura 14). En efecto, en la medida que nuevos pobladores llegaron a Huari se dio la necesidad de establecer nuevos suburbios para acomodar a los recién llegados. Dentro de este contexto, el principal reto para los investigadores de Huari es determinar las evidencias correspondientes a las ocupaciones tempranas de Huari que permanecen selladas por las enormes estructuras establecidas en el sitio con posterioridad.

Lo que resalta de esta discusión es que el abandono de varios asentamientos rurales huarpa parece coincidir con el inicial crecimiento de Huari. Al tiempo que los estilos de cerámica Cruz Pata y Okros iniciaron a ser manufacturados en el valle de Ayacucho, Huari ya se habría convertido en el único asentamiento más extenso de todo el valle de Ayacucho (Schreiber, 1992, p. 87), tal vez teniendo como único rival a Conchopata. Mientras Huari continuó acogiendo a un mayor número de residentes y su tamaño continuó expandiéndose (Isbell, 1984, p. 100; 1988, p, 173; 1997, p. 186), el número de los asentamientos humanos en el valle de Ayacucho decreció considerablemente. En la opinión de Lumbreras (2010, p. 37-38), este cambio representa una transición de rural a urbano, una transición sin antecedente alguno en toda la región de los Andes Centrales. En esta transformación, Huari y Conchopata parecen haber ejercido un rol activo. De esta discusión también se observa que la historia del desarrollo de Huari parece ser similar al de otros centros importantes como Susa, Uruk, Nekhen, Teotihuacan y Monte Albán; todos estos centros - se sostiene - nacieron en medio del conflicto (Adams, 1972, p. 21; Cowgill, 1997, p. 129; Blanton et al., 1993, p. 123; Marcus, 2008, p. 260) que resultó en la agrupación de la población en unidades políticas más extensos y mejor defendibles (Flannery \& Marcus, 2012, p. 472) en un esfuerzo por garantizar la autonomía. 


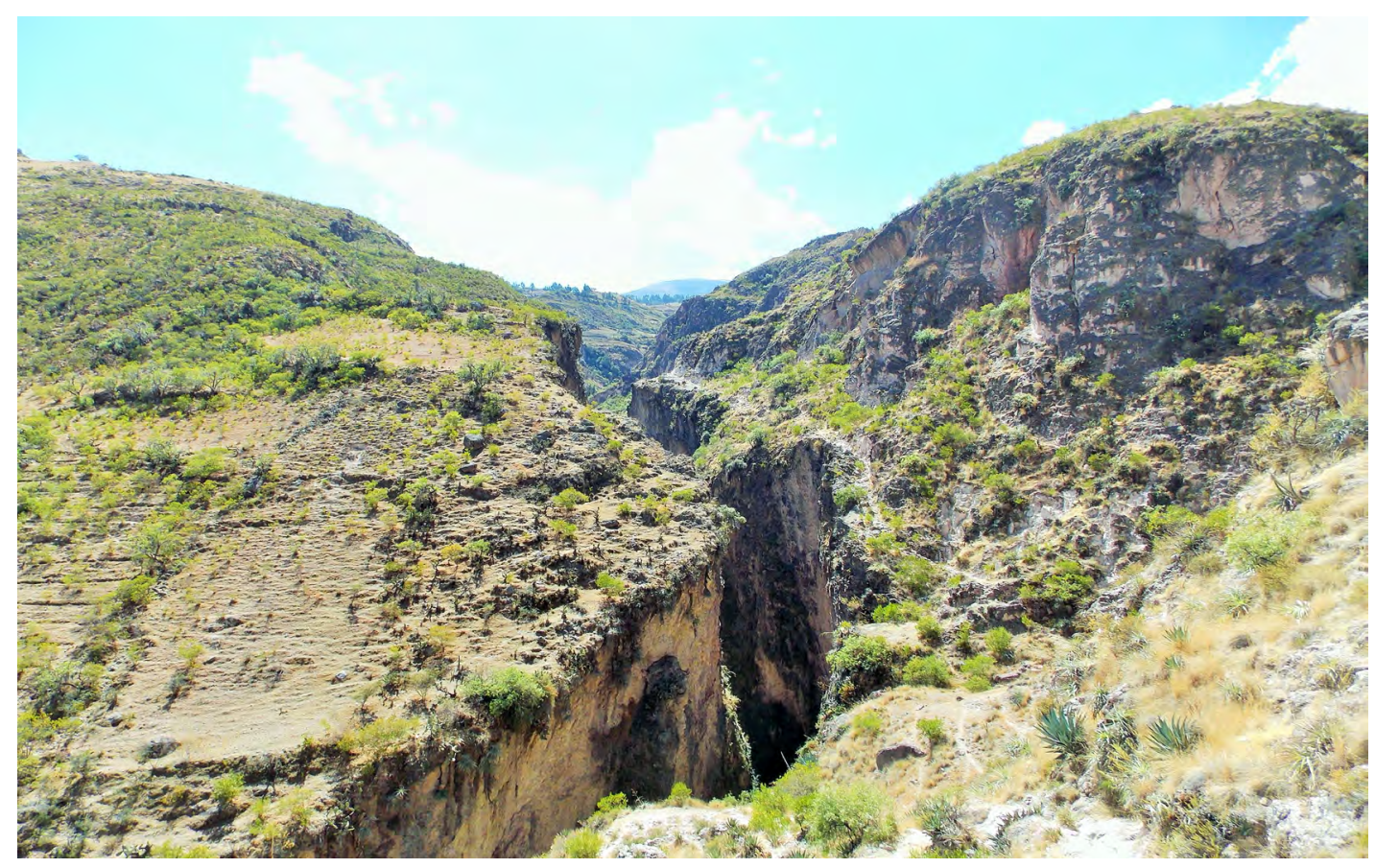

Figura 13. Quebrada profunda ubicada al norte de Huari.

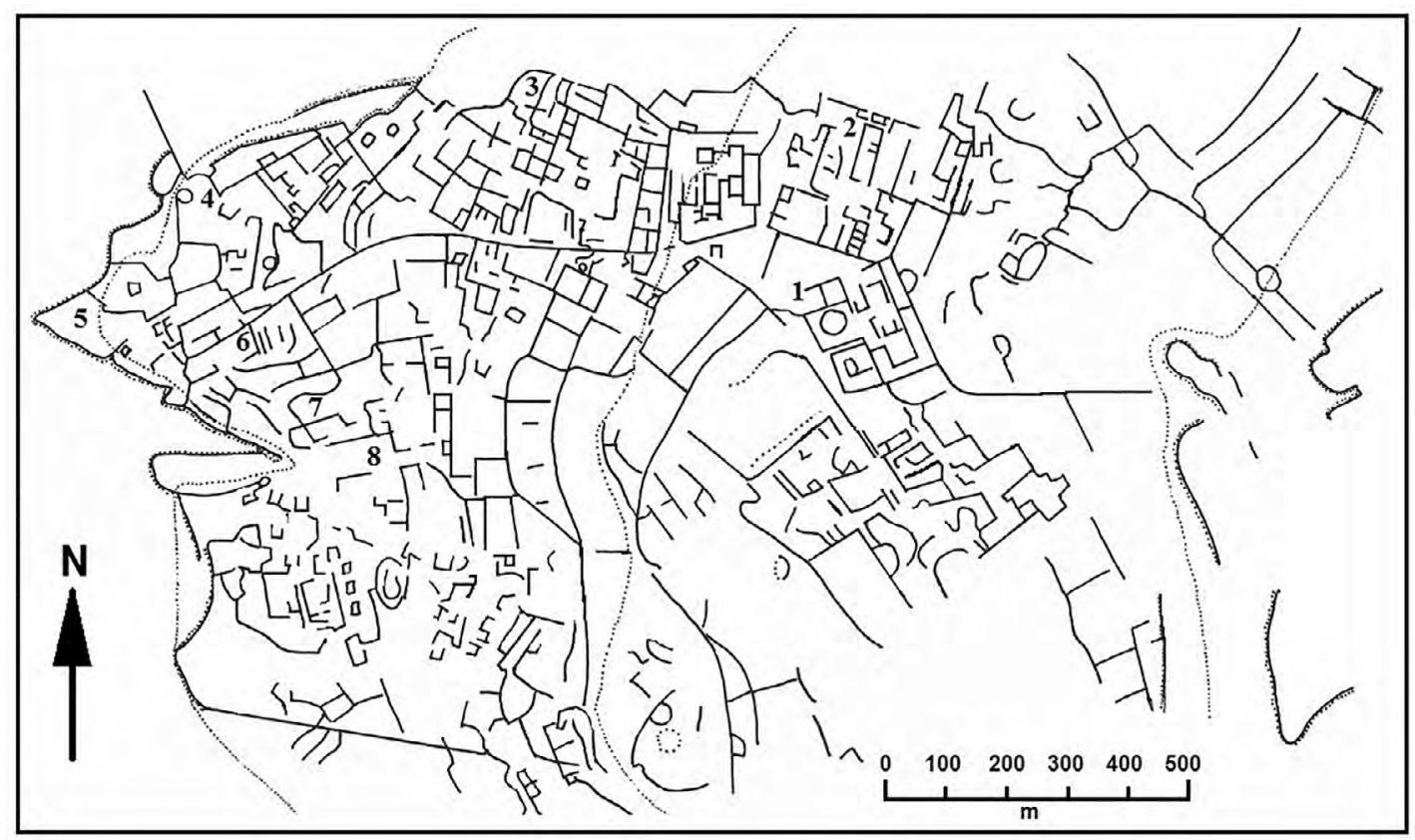

Figura 14. Mapa parcial del centro urbano de Huari 
Importante es agregar que a finales del Periodo Intermedio Temprano los asentamientos nasca de los valles de Palpa e Ingenio decrecieron considerablemente tanto en número, como en tamaño. Se sostiene que estos cambios se produjeron en respuesta a una prolongada sequía que afectó, forzando a un número considerable de la población nasca a establecerse en regiones vecinas, tal vez incluido el valle de Ayacucho (Eitel \& Mächtle, 2009, p. 27; Conlee, 2014, p. 245; Sossna, 2014, p. 231). Importante es recordar que este fue el tiempo cuando la cerámica manufacturada en el valle de Ayacucho llegó a asemejarse a la cerámica nasca (Lumbreras, 1980, p. 30). Está por determinarse si el crecimiento poblacional en el valle de Ayacucho tiene alguna relación con el abandono de muchos asentamientos nasca tardío. Esta es una tarea pendiente que un futuro cercano debe ser esclarecido. De confirmarse se podrá asegurar que la llegada de nuevos grupos poblaciones facilitó el crecimiento de centros como Huari y Conchopata.

Finalmente, evidencia arqueológica recientemente recuperada de la parte norte del valle de Ayacucho indica que a finales del Periodo Intermedio Temprano la interacción entre los habitantes de la costa sur y el valle de Ayacucho ya estaba bien establecida. La evidencia consiste en el hallazgo de las hojas de coca de una variedad que sólo existió en la costa (Plowman, 1979; Valdez, Taboada \& Valdez, 2015). La iconografía nasca en sus fases tardías representa personajes portando no sólo bolsas de coca, sino también masticando la coca (Silverman \& Proulx, 2002, p. 55; Proulx, 2006, p. 174, Plate 37; Shimada et al., 2006: Figuras 63 y 64). Dichas ilustraciones indican que la población nasca ya tenía familiaridad con la hoja de coca. Por cuanto no se conoce si la población del valle de Ayacucho haya también tenido dicha familiaridad antes del contacto con la costa sur, queda abierta la posibilidad que la coca, y sobre todo la práctica de chacchar la hoja de coca, fue introducido desde la costa sur (Valdez, Taboada \& Valdez, 2015). Esta es una información adicional que refuerza la idea de la interacción entre los habitantes de la costa sur y los del valle de Ayacucho.

\section{CONCLUSIÓN}

Este estudio presenta información proveniente de un asentamiento rural establecido en la inmediata periferia de la antigua ciudad de Huari, pero ocupado antes del auge de Huari. Al igual que otros asentamientos, éste había sido establecido en una colina elevada con amplia visibilidad. La cerámica recuperada del sitio indica que éste fue continuamente ocupado por un periodo largo, pero abandonado de manera rápida siguiendo la interacción que establecieron los habitantes del valle de Ayacucho con sus vecinos de la costa sur. Información disponible, aunque todavía limitado, indica que al tiempo que Huaqanmarka fue abandonado otros asentamientos contemporáneos del valle también quedaron despoblados. 
Al tiempo que los poblados rurales fueron abandonados, otros asentamientos iniciaron a crecer. Este fue el caso de Huari. Por lo tanto, existe poca duda que Huari fue beneficiario del abandono de los asentamientos rurales. La principal causa para este cambio, de una basada en asentamientos pequeños y definitivamente rurales hacia otra dominada por pocos pero grandes asentamientos, parece haber sido el conflicto. En efecto, la rápida agrupación de la población en pocos pero extensos asentamientos -como Huari y Conchopata- sugiere que el conflicto violento se incrementó en el valle de Ayacucho. Esta evidencia sugiere de este modo que la historia del desarrollo de Huari, especialmente en sus inicios, es similar a la de centros como Teotihuacan (Adams, 1977, p. 191; Cowgill, 1997, p. 129; Blanton et al., 1993, p. 129), Susa (Wright \& Johnson, 1975), Uruk (Adams, 1972, p. 21; 2012, p. 11; Flannery \& Marcus, 2012, p. 459) y Nekhen (Flannery \& Marcus, 2012, p. 404); en todos los casos aquí anotados las poblaciones se vieron en la necesidad de agruparse en pocos, mejor protegidos asentamientos, dando origen de este modo a los centros urbanos.

Al mismo tiempo, la evidencia del que dispone sugiere que la interacción con la costa sur parece que hizo que el conflicto en el valle de Ayacucho se incremente y así jugó rol importante en el desarrollo de la complejidad cultural de la región. Los especialistas han reconocido por mucho tiempo la ocurrencia de motivos nasca tardío en la cerámica del valle de Ayacucho (Rowe, Collier \& Willey, 1950, p, 128; Lumbreras, 1960, p. 156; Menzel, 1964, p. 7); sin embargo, los mecanismos de dicha interacción permanecen poco conocidos. Además de los motivos nasca tardío, la forma de las vajillas manufacturadas en el valle de Ayacucho guardan mayor acercamiento con los de nasca tardío, reforzando así que la interacción fue continua. Finalmente, resultado de este acercamiento fue la mejor sofisticación de la alfarería del valle de Ayacucho que además empezó a tener mejor acabado y más colorido (Schreiber, 2012, p. 38). Entretanto, la alfarería nasca empezó a perder su sofisticación y fino acabado. Tal como se anotó líneas adelante, parece que poblaciones nasca llegaron hasta el valle de Ayacucho; de ser así, detrás de la sofisticación de la alfarería ayacuchana tal vez estaban manos nasca. De este modo, se hace cada vez más evidente que la costa sur participó activamente en los asuntos internos de la población del valle de Ayacucho y esta tal vez fue la razón por la que la costa sur fue una de las primeras regiones incorporadas al dominio wari y también la razón por la que dicha región mantuvo una posición privilegiada dentro del Estado wari (Menzel, 1964, p. 68).

Resumiendo, lo relevante para los propósitos de esta discusión es que la interacción con la costa sur alteró el patrón de organización que prevaleció en el valle de Ayacucho por generaciones. La nueva tendencia fue vivir en asentamientos extensos en lugar de los pequeños y dispersos asentamientos rurales que caracterizó a la región por generaciones. Dicha preferencia posiblemente obedeció a que los asentamientos extensos eran mejor protegidos. Va más allá de la inicial intención de esta discusión determinar cuáles fueron las consecuencias y condiciones de tomar 
residencia dentro de las murallas de centros como Huari. Se puede especular que además de mostrar lealtad, una importante condición tal vez fue pagar tributo a los grupos de poder, responsables de la construcción de las murallas de Huari. Tal vez en respuesta a las condiciones sociales que prevalecieron, los refugiados tuvieron que aceptar las nuevas condiciones que se les presentaron. Finalmente, y así como Flannery y Marcus (2012, p. 472) anotan, aceptar dichas condiciones, como pagar tributo, posiblemente fue "el menor de los dos males."

AGRADECIMIENTOS: El trabajo de investigación efectuado en Huaqanmarka se llevó adelante con autorización del Ministerio de la Cultura (Resolución Directorial No. 289-DGPC-VMPCIC/MC). Fernando Huaqueriso, Yoni Llimpe, Roberto Tello, Edwin Guerrero y Eloy Espinoza colaboraron satisfactoriamente durante el trabajo de campo. Patricia J. Knobloch prestó su asistencia en la identificación de los varios estilos de cerámica hallados en Huaqanmarka.

\section{REFERENCIAS BIBLIOGRÁFICAS}

Adams, Richard E.W. (1977). Prehistoric Mesoamerica. Little, Brown and Company, Boston \& Toronto.

Adams, Robert McC. (1966). The Evolution of Urban Society: Early Mesopotamia and Prehispanic Mexico. Aldine Publishing Company, Chicago.

Adams, Robert McC. (1972). Spatial and temporal patterns of early urbanization. In The Uruk Countryside: the Natural Setting of Urban Societies, editado por R. McM Adams y H. J. Nissen, pp. 9 - 33. University of Chicago Press, Chicago.

Adams, Robert McC. (2012). Ancient Mesopotamian urbanism and blurred disciplinary boundaries. Annual Review of Anthropology 41: 1-20.

Allen, Mark W. y Elizabeth N. Arkush. (2006). Introduction: archaeology and the study of war. In The Archaeology of Warfare: Prehistoric Raiding and Conquest, editado por E. N. Arkush y M. W. Allen, pp. 1-19. University of Florida Press, Gainesville.

Arkush, Elizabeth N. y Charles Stanish. (2005). Interpreting conflict in the Andes: implications for the archaeology of warfare. Current Anthropology 46:3-28.

Benavides, Mario. (1976). Sitios arqueológicos de Ayacucho. Universidad de Huamanga, Ayacucho.

Bennett, Wendell C. (1953). Excavations at Wari, Ayacucho, Peru. Yale University Publications in Anthropology 49, New Haven.

Bennett, Wendell C. y Junius B. Bird. (1949). Andean Culture History. The American Museum of Natural History, New York. 
Blanton, Richard E., Stephen A. Kowalewski, Gary M. Feinman y Laura M. Finsten (1993). Ancient Mesoamerica: a Comparison of Change in Three Regions $\left(2^{\text {nd }}\right.$. Edition). Cambridge University Press, Cambridge.

Chesson, Meredith S. y Nathan Goodale. (2014). Population aggregation, residential storage and socioeconomic inequality at Early Bronze Aga Numayra, Jordan. Journal of Anthropological Archaeology 35:117-134.

Childe, V. Gordon. (1951). Man Makes Himself. The New American Library of World Literature, INC, London.

Cieza de León, Pedro. (1973 [1553]). La crónica del Perú. Ediciones PEISA Biblioteca Peruana, Lima.

Conlee, Christina A. (2014). Nasca culture integration and complexity: a perspective from the site of La Tiza. Journal of Anthropological Archaeology, 35, pp. 234-247.

Cook, Anita G. (2012). The coming of the staff deity. En L. E. Oscar (Ed.), Wari, Lords of the Ancient Andes (pp. 103-121). The Cleveland Museum of Art \& Thames \& Hudson, New York.

Cowgill, George L. (1997). State and Society at Teotihuacan, Mexico. Annual Review of Anthropology, 26, pp. 129-161.

Cowgill, George L. (2004). Origins and development of urbanism: an archaeological perspective. Annual Review of Anthropology, 33, pp. 525-549.

Eitel, Bernhard y Bertil Mätchel. (2009). Man and environment in the eastern Atacama Desert (southern Peru): Holocene climate changes and their impact on pre-Columbian cultures. En M. Reindel y G. A. Wagner (Ed.), New Technologies for Archaeology: Multidisciplinary Investigations in Palpa and Nasca, Peru, pp. 17-37. Spinger-Verglag, Berlin, Heidelberg.

Elliott, Michelle. (2005). Evaluating evidence for warfare and environmental stress in settlement pattern data from Malpaso Valley, Zacatecas, Mexico. Journal of Anthropological Archaeology, 24, pp. 97-315.

Finucane, Brain C. (2008). Trophy heads from Nawimpukio, Peru: physical and chemical analysis of Huarpa-era modified human remains. American Journal of Physical Anthropology, 135, pp. 75-84.

Flannery, Kent V. (1972). The Cultural Evolution of Civilizations. Annual Review of Ecology and Systematics, 3, pp. 399-426.

Flannery, Kent V. y Joyce Marcus. (2003). The origin of war: new C14 dates from ancient Mexico. Proceedings of the National Academy of Sciences (USA) 100 (pp. 11801-11805). 
Flannery, Kent V. y Joyce Marcus. (2012). The Creation of Inequality: How our Prehistoric Ancestors Set the Stage for Monarchy, Slavery, and Empire. Harvard University Press, Cambridge \& London.

Haymes, Raymond B. (1983). The settlement patterns of the Yanomamo population block: a behavioral ecological interpretation. En R. B. Haymes y W. T. Vickers (Ed.), Adaptive Responses of Native Amazonians (pp. 393-427). Academic Press, New York.

Hyslop, John. (1984). The Inka Road System. Academic Press, New York.

Isbell, William H. (1984). Huari urban prehistory. En A. Kendall (Ed.), Current Archaeological Projects in the Central Andes (pp. 95-135). British Archaeological Reports International Series 210. Oxford.

Isbell, William H. (1987). Conchopata, ideological innovator in Middle Horizon 1A. Ñawpa Pacha, 22-23, pp. 91-134.

Isbell, William H. (1988). City and state in Middle Horizon Peru. En R. Keatinge (Ed.), Peruvian Prehistory, (pp. 164-189). Cambridge University Press, Cambridge.

Isbell, William H. (1991). Conclusion: Huari administration and the orthogonal cellular architecture horizon. En W.H. Isbell \& G.F. McEwan (Ed.), Huari Administrative Structure: Prehistoric Monumental Architecture and State Government, pp. Pp. 293-315. Dumbarton Oaks, Washington D.C.

Isbell, William H. (1997). Reconstructing Huari: a cultural chronology for the capital city. En L. Manzanilla (Ed.), Emergence and Change in Early Urban Societies (pp. 181-227). Plenum Press, New York y London.

Isbell, William H. (2008). Wari and Tiwanaku: international identities in the Central Andean Middle Horizon. En H. Silverman \& W.H. Isbell (Ed.), Handbook of South American Archaeology (pp. 731-759). Springer, New York.

Isbell, William H., Christine Brewster-Wray y Lynda. A. Spickard. (1991). Architecture and spatial organization at Huari. En W.H. Isbell \& G.F. McEwan (Ed.), Huari Administrative Structure: Prehistoric Monumental Architecture and State Government, pp. 19-54. Dumbarton Oaks, Washington D.C.

Isbell, William H. y Anita G. Cook. (1987). Ideological origins of an Andean conquest state. Archaeology, 40 (4), 27-33.

Isbell, William H. y Patricia J. Knobloch. (2009). SAIS - The origin, development, and dating of-Huari iconography. En M. Young-Sánchez (Ed.), Tiwanaku, pp. 165210. Mayer Center for Precolumbian and Spanish Colonial Art at the Denver Art Museum. Denver Art Museum, Boulder. 
Isbell William H. y Gordon F. McEwan. (1991). A history of Huari studies and introduction to current interpretations. En W.H. Isbell \& G.F. McEwan (Ed.), Huari Administrative Structure: Prehistoric Monumental Architecture and State Government, (pp. 1-17). Dumbarton Oaks, Washington D.C.

Isbell, William H. y Katharina J. Schreiber. (1978). Was Huari a state? American Antiquity 43 (3), pp. 372-389.

Isbell, William H. y Magaret Young-Sánchez. (2012). Wari's Andean legacy. En L. E. Oscar (Ed.), Wari, Lords of the Ancient Andes, (pp. 251-267). The Cleveland Museum of Art \& Thames \& Hudson, New York.

Knobloch, Patricia J. (1991). Stylistic date of ceramics from the Huari centers. En W.H. Isbell \& G.F. McEwan (Ed.), Huari Administrative Structure: Prehistoric Monumental Architecture and State Government (pp. 247-258). Dumbarton Oaks, Washington, D.C.

Knobloch, Patricia J. (2012). Archives in clay the styles and stories of Wari ceramic artists. En L. E. Oscar (Ed.), Wari, Lords of the Ancient Andes (pp.122-142). The Cleveland Museum of Art \& Thames and Hudson, New York.

Knobloch, Patricia J. (2013). An Early Intermediate Period deposit of Huarpa style ceramics from the Site of Huari, Department of Ayacucho, Peru (1989). Arkeo Ayacucho Peru.

Kroeber, Alfred L. (1944). Peruvian Archaeology in 1942. Viking Fund Publications in Anthropology 4, Wenner-Green Foundation for Anthropological Research, New York.

Leach, Edmund R. (1990). Political Systems of Highland Burma: a Study of Kachin Social Structure, Monographs in Social Anthropology 44. The Athlone Press, London School of Economics London and Atlantic Highlands, NJ.

LeBlanc, Steven A. (2006). Warfare and the development of social complexity. En E. N. Arkush \& M. W. Allen (Ed.). The Archaeology of Warfare: Prehistories of Raiding and Conquest (pp. 437-68). University Press of Florida, Gainesville.

Leoni, Juan B. (2006). Ritual and society in Early Intermediate Period Ayacucho: a View from Ñawinpukyo. En W.H. Isbell \& H. Silverman (Ed.), Andean Archaeology III: North and South (pp. 279-306). Springer, New York.

Leoni, Juan B. (2010). Early Intermediate Period and Middle Horizon Funerary Practices in Ayacucho: a View from the site of Ñawinpukyo. Nawpa Pacha, 30, pp. 65-90.

Lumbreras, Luis G. (1959). Esquema arqueológico de la sierra central del Perú. Revista Nacional XXVIII, pp. 63-116. 
Lumbreras, Luis G. (1960). La cultura Wari. Etnología y Arqueología, 1, pp. 130-227. Instituto de Etnología y Arqueología, Universidad Nacional Mayor de San Marcos, Lima.

Lumbreras, Luis G. (1974). The Peoples and Cultures of Ancient Peru. Smithsonian Institution Press, Washington, D.C.

Lumbreras, Luis G. (1975). Las Fundaciones de Huamanga: hacia una prehistoria de Ayacucho. Club de Huamanga, Lima.

Lumbreras, Luis G. (1980). El Imperio Wari. En Historia del Perú, vol. 2, pp. 9-91. Editorial J. Mejia Baca, Lima.

Lumbreras, Luis G. (1986). Una nueva visión del antiguo Perú. Municipalidad de Lima.

Lumbreras, Luis G. (2010). Plan de manejo del complejo arqueológico Wari, Ayacucho. Gobierno Regional de Ayacucho, Plan Copesco Nacional, Ayacucho.

Lumbreras, Luis G. (2012). Introduction. En, L. E. Oscar (Ed.), Wari, Lords of the Ancient Andes (pp.1-3). The Cleveland Museum of Art \& Thames and Hudson, New York.

MacNeish, Richard S. (1981). Synthesis and Conclusions. En R. S. MacNeish (Ed.), Prehistory of the Ayacucho Basin, Peru, Vol II: Excavations and Chronology (pp.199257). R. S. Peabody Foundation for Archaeology. The University of Michigan Press, Ann Arbor.

Makowski, Krzysztof. (2008). Andean urbanism. En H. Silverman \& W.H. Isbell (Ed.) (pp. 633-657). Springer, New York.

Marcus, Joyce. (2008). The archaeological evidence for social evolution. Annual Review of Anthropology, 37, pp. 251-266.

McEwan, Gordon F. (1991). Investigations at the Pikillacta Site: a provincial Huari center in the Valley of Cuzco. En W.H. Isbell \& G.F. McEwan (Ed.), Huari Administrative Structure: Prehistoric Monumental Architecture and State Government (pp. 93-119). Dumbarton Oaks, Washington D.C.

McEwan, Gordon F. (1996). Archaeological investigations at Pikillacta, a Wari site in Peru. Journal of Field Archaeology 23, pp. 169-86.

McEwan, Gordon F. (2005). Pikillacta: The Wari Empire in Cusco. University of Iowa Press, Iowa City.

McEwan, Gordon F. y Patrick R. Williams. (2012). The Wari built environment: landscape and architecture of empire. En L. E. Oscar (Ed.), Wari, Lords of the Ancient Andes (pp. 65-81). The Cleveland Museum of Art \& Thames and Hudson, New York.

Mcintosh, Jane R. (2005). Ancient Mesopotamia: New Perspectives. Denver and Sta. Barbara, ABC-CLIO, Denver. 
Menzel, Dorothy. (1964). Style and time in the Middle Horizon. Nawpa Pacha, 2, pp. 1-106.

Millon, Rene. (1973). Painting, writing, and polity at Teotihuacan. American Antiquity, 38, pp. 294-314.

Nash, Donna y R. Patrick Williams. (2009). Wari political organization on the southern periphery. En J. Marcus \& P. R. Williams (Ed.), Andean Civilization: a Tribute to Michael E. Moseley, pp. 257-276. Cotsen Institute of Archaeology Press, UCLA, Los Angeles.

Nissen, Hans J. (2002). Uruk: key site of the period and key site of the problem.En J. N. Postgate (Ed.), Artifacts of Complexity: Tracking the Uruk in the Near East, (pp. 1-17). British School of Archaeology in Iraq, London.

Ochatoma, José A. y Martha Cabrera. (1999). Descubrimientos del área ceremonial de Conchopata, Huari. XII Congreso Peruano del Hombre y la Cultura Andina Luis G. Lumbreras, 1, pp. 212-245. Universidad Nacional de San Cristóbal de Huamanga, Ayacucho.

Pallock, Susan. (1999). Ancient Mesopotamia. Cambridge University Press, Cambridge.

Pérez Calderón, Ismael. (2001). Investigaciones en la periferia del complejo Huari. In XII Congreso Peruano del Hombre y la Cultura Andina Luis G. Lumbreras, 2, pp. 246270. Universidad Nacional de San Cristóbal de Huamanga, Ayacucho.

Pérez Calderón, Ismael. (2012). Asentamientos periféricos del centro urbano de Conchopata, Ayacucho. Arqueología y Sociedad, 25, pp. 143-168.

Plowman, Timothy. (1979). Botanical perspectives on coca. Journal of Psychedelic Drugs, 11 (1-2), 103-117.

Proulx, Donald A. (1994). Stylistic Variation in Proliferous Nasca Pottery. Andean Past 4: 91-107.

Proulx, Donald A. (2006). A Source Book of Nasca Iconography. University of Iowa Press, Iowa City.

Redmond, Elsa M. y Charles S. Spencer. (2006). From raiding to conquest: warfare strategies and early state development in Oaxaca, Mexico. En E. N. Arkush \& M. W. Allen (Ed.), The Archaeology of Warfare: Prehistories of Raiding and Conquest, pp.336-393. University Press of Florida, Gainesville.

Roscoe, Patrick. (2008). Settlement fortification in village and "Tribal" society: evidence from contact near New Guinea. Journal of Anthropological Archaeology 27, pp. 507-519.

Rowe, John H. (1956). Archaeological explorations in southern Peru. American Antiquity 22, pp. 135-51. 
Rowe, John H. (1963). Urban settlements in Ancient Peru. Ñawpa Pacha 1, pp. 1-28.

Rowe, John H., Donald Collier y Gordon R. Willey. (1950). Reconnaissance notes on the site of Huari, near Ayacucho, Peru. American Antiquity 16, pp. 120-137.

Schreiber, Katharina J. (1987). From state to empire: the expansion of the Wari State outside the Ayacucho Basin. En J. Haas, S. Pozorski \& T. Pozorski (Ed.), The Origins and Development of the Andean State, (pp. 91-96). Cambridge University Press, Cambridge.

Schreiber, Katharina J. (1992). Wari Imperialism in Middle Horizon Peru, Anthropological Papers 87. Museum of Anthropology University of Michigan, Ann Arbor.

Schreiber, Katharina J. (1999). Regional approaches to the study of prehistoric empires: examples from Ayacucho and Nasca, Peru. En B. R. Billman \& G. M. Feinman (Ed.), Settlement Pattern Studies in the Americas: Fifty Years since Virú, (pp. 160-71). Smithsonian Institution Press, Washington, DC.

Schreiber, Katharina J. (2001). The Wari Empire of Middle Horizon Peru: the epistemological challenge of documenting an empire without documentary evidence. En S. E. Alcock, T. N. D’Altroy, K. D. Morrison \& C. M. Sinopoli (Ed.), Empires, (pp. 70-92). Cambridge University Press, Cambridge.

Schreiber, Katharina J. (2012). The rise of an Andean Empire. In Wari, Lords of the Ancient Andes, en L. E. Oscar (Ed.). The Cleveland Museum of Art \& Thames and Hudson (pp.31-45), New York.

Shimada, Izumi, H. Baba, K. Shinoda y M. ONO (eds.). (2006). Nasca, Wonders of the World: Messages Etched on the Desert Floor. Tokyo: Toppan Printing Co, Ltd.

Silverman, Helaine y Donald A. Proulx. (2002). The. Malden and Oxford. Blackwell Publishing.

Sinopoli, Carla M. (1994). The archaeology of empires. Annual Review of Anthropology, 23, pp. 159-180.

Smith, Monica L. (2014). The archaeology of urban landscapes. Annual Review of Anthropology, 43, pp. 307-323.

Sossna, Volker. (2014). Impacts of Climate Variability on Prehispanic Settlement Behavior in South Peru: the northern Rio Grande drainage between 15000 BCE and 1532 CE. Unpublished Ph.D dissertation der Mathematisch-Naturwissenschaftlichen Fakultät der Christian-Albrechts-Universität zu Kiel vorgelegt von, Bonn.

Stanish, Charles. (2001). The origin of state societies in South America. Annual Review of Anthropology, 30, pp. 41-64.

Trigger, Bruce C. (1990). Monumental architecture: a thermodynamic explanation of symbolic behaviour. World Archaeology, 22, pp. 119-132. 
Tung, Tiffiny A. (2012). Violence, Ritual and the Wari Empire: a Social Bioarchaeology of Imperialism in the Ancient Andes. University of Florida Press, Gainesville.

Tung, Tiffiny A. y Kelly J. Knudson. (2011). Identifying locals, migrants, and captives in the Wari heartlands: a bioarchaeological and biochemical study of human remains from Conchopata, Peru. Journal of Anthropological Archaeology, 30, pp. 247-261.

Valdez, Lidio M. (1996). The Early Intermediate Period beyond the Ayacucho Valley, Peru, en D. Meyer, P. Dawson y D. Hannan (Ed.). Debating Complexity (pp. 600-606). The Archaeological Association of the University of Calgary, Calgary.

Valdez, Lidio M. (1997). Ecology and ceramic production in an Andean community: a reconsideration of the evidence. Journal of Anthropological Research, 52, pp. 65-85.

Valdez, Lidio M. (2014). The earliest fortifications of the Peruvian south coast. Ñawpa Pacha, 34, pp. 201-222.

Valdez, Lidio M., Juan Taboada y J. Ernesto Valdez. (2015). Ancient use of coca leaves in the Peruvian central highlands. Journal of Anthropological Research, 71, pp. 231-258.

Valdez, Lidio M. y J. Ernesto Valdez. (2016). Highland and coastal interaction: new evidence from the ancient city of Huari, Ayacucho Valley, Peru. En Margaret Patton and Jessica Manion (Ed.), Trading Spaces: The Archaeology of Interaction, Migration and Exchange (pp. 91-108). Proceedings of the 46th Annual Chacmool Archaeology Conference. Chacmool Archaeology Association of the University of Calgary, Calgary.

Valdez, Lidio M. y J. Ernesto Valdez. (2017). From rural to urban: archaeological research in the periphery of Huari, Ayacucho Valley, Peru. Journal of Anthropology (pp. 1-14).

Willey, Gordon R. (1948). A functional analysis of "Horizon Styles" in Peruvian archaeology. En W. C. Bennett (Ed.), A Reappraisal of Peruvian Archaeology (Vol. 13 (4), Part 2. 8-15). Memoirs of the Society for American Archaeology.

Williams, R. Patrick. (2001). Cerro Baúl: a Wari center in the Tiwanaku frontier. Latin American Antiquity, 12 (1), 67-83.

Williams R. Patrick y Donna Nash. (2002). Imperial interactions in the Andes: Wari and Tiwanaku at Cerro Baúl. En W. H. Isbell y H. Silverman (Ed.). Andean Archaeology I: Variation and Sociopolitical Organization, (pp. 243-265). Kluwer Academic/Plenum, New York. 
Wright, Henry T. (1977). Toward an explanation of the origin of the state. En J. Hill (Ed.). Explanation of Prehistoric Change (pp. 215-230). University of New Mexico Press, Albuquerque.

Wright, Henry T. y Gregory A. Johnson. (1975). Population, exchange, and early state formation in southwestern Iran. American Anthropologist, 77, pp. 267-289.

\section{SOBRE LOS AUTORES}

\section{Lidio M. Valdez}

Licenciado en Arqueología por la Universidad Nacional de San Cristobal de Huamanga, y Doctor en Filosofía (1998), University of Calgary (Canada). Sus trabajos más recientes son en relación a la ocupación Inka en el Valle de Acari.

Actualmente es profesor adjunto en el Department of Anthropology and Archaeology, University of Calgary, Canada.

\section{Julio Ernesto Valdez Cárdenas}

Licenciado en Arqueología por la Universidad Nacional San Cristóbal de Huamanga; Licenciado en Educación Secundaria: Especialidad de Historia y Geografía, por la Universidad Nacional San Cristóbal de Huamanga. Docente Investigador, en la Universidad Nacional San Cristóbal de Huamanga, Ayacucho, Perú. Magister en Arqueología y estudios de Maestría en Gestión Pública por la Universidad César Vallejo. Su estudio se centra en sociedades complejas prehispánicas, y sobre en el estudio de la presencia de la cultura Warpa, Wari, Chanka e Inka en la región de Ayacucho. Además, en temas como turismo, problemática educativa, historia y geografía. Ha publicado sobre la cultura Chanka, sobre caminos prehispánicos, y artículos científicos sobre arqueología local y regional de la sierra sur central del Perú en revistas de circulación nacional como internacional. Fundador y director de la Revista Arqueológica Warpa, que trata sobre temas regionales y locales, en temáticas de arqueología, economía, antropología, geografía e historia. Es coautor del libro: "Arqueología del Valle de Ayacucho"; es autor del libro: "Asentamientos Chanka: Una respuesta al medio ambiente, Ayacucho Perú," y co-autor del libro "Ñaupa Ñan: Uniendo la ciudad imperial del Wari con el valle de Huanta." 